\title{
Envejecimiento y Enfermedades Respiratorias en las Personas Adultas Mayores. El caso de un centro de jubilados de Rio Gallegos
}

\author{
Aging and Respiratory Diseases in the Elderly. The case of a Rio Gallegos retirement \\ center
}

Roxana Katherina Oyarzo Saldivia, Sara Ojeda, María Laura Ivanissevich roxanaoyarzo23@gmail.com,sojeda@uarg.unpa.edu.ar,mivanissevich@uarg.unpa.edu.ar ISISC - UARG

Universidad Nacional de la Patagonia Austral

Santa Cruz- Argentina

Recibido: 02/04/2020. Aceptado: 17/11/2020

\section{RESUMEN}

En la ciudad de Rio Gallegos no abundan los estudios sobre la prevalencia de enfermedades respiratorias agudas y crónicas en los adultos mayores. A través de una beca de investigación para alumnos avanzados de la Licenciatura en Enfermería se ha indagado en un barrio icónico de la ciudad capital -el barrio Belgrano- a la población de personas adultas mayores que asisten a un Centro de Jubilados ubicado en el centro barrial, con el fin de obtener la prevalencia de enfermedades respiratorias y relevar hábitos pertinentes. El tipo de investigación ha sido cuanti-cualitativa, descriptiva de corte transversal. Los resultados han mostrado que las respiratorias no son las disfunciones que padece la mayoría de la población considerada, aunque el desconocimiento sobre las vacunas asociadas a enfermedades respiratorias emerge como un indicador importante a tener en cuenta para políticas públicas en salud y se ha destacado la bronquitis aguda invernal como alteración respiratoria aguda prevalente.

Palabras clave: Persona Adulta Mayor; Enfermedades Respiratorias; Envejecimiento; Centro de Jubilados Rio Gallegos.

\begin{abstract}
In the city of Rio Gallegos, studies on the prevalence of acute and chronic respiratory diseases in older adults are not abundant. Through a research scholarship for advanced students of the Bachelor of Nursing, the population of the elderly who attend a Retirement Center located in the neighborhood center has been investigated in an iconic neighborhood of the capital city the Belgrano neighborhood., in order to obtain the prevalence of respiratory diseases and relieve relevant habits. The type of research has been quantitative-qualitative, descriptive, cross-sectional. The results have shown that respiratory diseases are not the dysfunctions suffered by the majority of the population considered, although the lack of knowledge about vaccines associated with respiratory diseases emerges as an important indicator to take into account for public health policies and bronchitis has been highlighted. winter acute as prevalent acute respiratory disturbance.
\end{abstract}


Keywords: Elderly Person; Respiratory diseases; Aging; Rio Gallegos Retiree Center.

\section{INTRODUCCIÓN}

El envejecimiento en América latina y el Caribe ha presentado un crecimiento exponencial. La CEPAL (2012) indica que mientras que para la década del 70 representaba el 5,6\% de la población, en el 2010 era del $10 \%$ y se espera que para el 2050 la cifra se triplique y al final del s XXI ascienda a 236 millones, el $36 \%$ de la población.

Esta transición demográfica transita diversas etapas, Argentina según los datos del INDEC (2010) es uno de los países más envejecidos de la región con el 14,3\% de su población mayor de 60 años lo que indica un proceso de envejecimiento avanzado. Se estima que esta población seguirá creciendo a lo largo de este siglo y que para el 2050 un cuarto de la población Argentina tendrá más de 60 años.

El proceso de envejecimiento tiene un ritmo diferente de comportamiento en las distintas provincias argentinas, datos del censo INDEC (2010), indican que el crecimiento del número de personas adultas mayores de 60 años en la provincia de Santa Cruz pasaría del 8,03\% al 15,33\% en el año 2040 lo que plasmaría un crecimiento de un $90 \%$ en treinta años.

Este vertiginoso cambio demográfico representa una crisis del cuidado de las personas adultas mayores (PAM), que interpela no solo al sistema de salud, sino a la comunidad entera en busca de respuestas a las demandas que genera. Por ello es importante la aplicación de un modelo de atención socio sanitario integral, global, interdisciplinario y armónico, inserto en la comunidad, un enfoque que propone la participación activa del usuario y su familia, en su propio proceso de atención con el fin de lograr y/o mantener el máximo grado de autonomía.

Touceda, M y otros (2015) hacen referencia que las PAM constituyen un grupo heterogéneo con variabilidad individual, cada una de ellas envejece de manera diferente, ya que interactúan factores intrínsecos y extrínsecos relacionados con lo social económico cultural ambiental, por lo que la incidencia y prevalencia de enfermedades crónicas se presentan de forma diferente.

Las enfermedades respiratorias son una de las primeras diez causas de la morbilidad y mortalidad mundial (OMS 2018) y las PAM son los más susceptibles de adquirirlas, ya sean las de tipo crónicas como la bronquitis, enfermedad pulmonar obstructiva, asma bronquial; o de carácter agudo como las infecciones respiratorias altas seguido de neumonías y bronquitis. Susceptibilidad que podría vincularse entre otras causas, a los cambios o ciertas modificaciones anatómicas y estructurales que se producen por el proceso de envejecimiento en el aparato respiratorio.

En Argentina, todos los años se verifica un progresivo aumento de los casos de infecciones respiratorias agudas (IRAs) en la época invernal, asociado a un incremento en la demanda de atención, número de hospitalizaciones y de la mortalidad por causas respiratorias.

Datos del Ministerio de Salud y Ambiente de Santa Cruz para el periodo 2011 a 2015 refieren que la mortalidad por enfermedades respiratorias según grupo etario entre los 65 y 74 años corresponde a más de 40 casos. Datos del 2015 muestran IRAs por departamento geográfico, para el departamento Güer Aike -donde se ubica la ciudad capital Rio Gallegos- le corresponden 5 casos. No se identifica la prevalencia de Enfermedades Respiratorias en los Adultos Mayores para esta ciudad

Para el presente estudio se propuso investigar la prevalencia de enfermedades respiratorias y relevar hábitos pertinentes, en una población específica; la población adulta mayor en el Centro de Jubilados "Encuentro de Amigos", del barrio Belgrano de la ciudad Rio Gallegos (Santa Cruz-Argentina) en el año 2019, con alcance descriptivo y de corte transversal. 
Los principales resultados aportan datos epidemiológicos específicos de la prevalencia de la enfermedades respiratorias en las PAM, que pueden servir de insumo a las instituciones de salud como así también ponen en relieve la importancia de brindar educación para la salud en esta población, en una acción responsable y compartida entre el estado y los actores sociales del centro de jubilados, potenciando las alianzas intersectoriales y favoreciendo la construcción de espacios empoderados para hacer más efectivas las acciones de promoción, prevención y asistencia de la salud.

\section{ENVEJECIMIENTO}

Schüller, P y otros (1999) expresan que: "El envejecimiento es un proceso lento, progresivo e inevitable caracterizado por disminución paulatina de la actividad fisiológica y de la capacidad de adaptación al entorno, acumulándose exponencialmente los procesos patológicos edad-dependiente", reconocen que el envejecimiento del ser humano está presente durante toda la vida adulta y que se acentúa progresivamente con el aumento de la edad, resaltando que la principal característica del proceso es la limitación progresiva en las capacidades y competencias funcionales de adaptación y de interacción del ser humano con su medio ambiente biológico, físico, psicológico y social.

Las Naciones Unidas consideran como adultos mayores a quienes tienen una edad mayor o igual de 60 años en los países en vías de desarrollo y 65 años o más a quienes se encuentran en países desarrollados.

La clasificación de las personas adultas mayores (PAM) según la edad parte desde 1982 con Neugarten y en 2004 con Villamil y Montañéz. Establecen dos categorías de vejez: los jóvenes viejos que comprenden de 55 a 75 años y la de los viejos viejos, de 75 años en adelante; fundamentando esta clasificación no en la edad en sí misma, sino en las características sociales y de salud. Riley (1988) y Neugarten (1999) modifican estos criterios y propone tres grupos de viejos en función de su edad: los viejos-jóvenes, entre 65 y 74 años, los viejos-viejos entre 75-85 años, y aquellos con 86 años y más, que son los viejos-muy viejos. Por otra parte la Organización Mundial de la Salud (OMS) (2005) propone catalogarlos como de edad avanzada a aquellos comprendidos de los 60 a 74 años, como viejos o ancianos a los 75 a 90 años; y a los mayores de 90 años como grandes viejos o grandes longevos, en otras clasificaciones se toman en cuenta a este último grupo con una subdivisión adicional los nonagenarios entre 90 y 100 años, centenarios entre 100 y 110 años y según la Asociación Internacional de Psicogeriatría y el Gerontology Research Group (García Pulgarín (2005) como supercentenarios a quienes tendrían más de 110 años.

Ham, Chande, R. (2000) expresa que: "La vejez es un fenómeno multidimensional que implica aspectos biológicos, físicos, mentales, sociales, económicos, psicológicos e incluso políticos, relacionados unos con otros, de tal manera que no se puede hacer referencia a uno sin mencionar a los demás." Los procesos de envejecimiento se mencionan como; el fisiológico, visto desde parámetros biológicos normales y relación con el medio, el patológico cuando la presencia de enfermedades altera el curso normal del anterior, el activo, cuando se optimizan las oportunidades de bienestar físico, social y mental, con el fin de mantener su autonomía y funcionalidad. Así mismo al decir de Moragas (1991) citado de Acevedo, Alemán. J. y otros (2012), la vejez se puede conceptualizar como: cronológica, asociada al aspecto biológico y el etario; funcional, asociada a la capacidad o limitación y la vejez etapa vital, como el ingreso a una etapa distinta a las que le antecedieron, con una realidad propia, limitada solamente por condiciones objetivas externas y por las subjetivas de la persona. 
La OMS, en el año 2002 dio a conocer el documento "Envejecimiento activo: un marco político", definiéndolo como "El proceso donde se optimizan las oportunidades de salud, participación y seguridad a fin de mejorar la calidad de vida de las personas a medida que envejecen.", se desprenden cuatro aspectos fundamentales que hacen referencia a salud mental y física, participación en la sociedad, seguridad y aprendizaje durante toda la vida.

El Programa Nacional de Envejecimiento Activo y Salud (PRONEAS) (Resolución 1714/2012), busca articular acciones dirigidas a las PAM con el fin de establecer un modelo de salud integral, que fortalezca la accesibilidad al sistema de salud y mejore la calidad de vida.

\subsection{Los cambios fisiológicos del envejecimiento}

El envejecimiento de la población se ha convertido en una cuestión de primordial importancia, se proyecta que para el 2050 el porcentaje de adultos mayores (AM) aumentara y se duplicara del $11 \%$ al $22 \%$. Este cambio demográfico plantea un problema importante en materia de acciones múltiples e integradas y de recursos, sobre todo de recursos humanos especializados en la atención de salud y cuidados.

Argentina es uno de país demográficamente envejecido y según el censo 2010, la Patagonia es la región con mayor crecimiento relativo que pasa del $4,8 \%$ a un $5,2 \%$ y particularmente Santa Cruz con una Tasa de crecimiento medio anual intercensal del 37,6 \% (2001-2010).

Las PAM son los más susceptibles de adquirir enfermedades de tipo respiratoria ya sean las de tipo crónicas como la bronquitis, enfermedad pulmonar obstructiva, asma bronquial; o de carácter agudo como las infecciones respiratorias altas seguido de neumonías y bronquitis. Susceptibilidad que podría vincularse a los cambios o ciertas modificaciones anatómicas y estructurales que se producen en el aparato respiratorio, entre otras causas. A nivel de las vías aéreas hay aumento de la rigidez y luz traqueal, disminución de la cuantía y enlentecimiento de cilios, aumento de tamaño de glándulas mucosas bronquiales. A nivel del parénquima pulmonar aparece perdida del resorte elástico pulmonar, menor capacidad de retracción histica, agrandamiento de conductos, aplanamiento de los alveolos, perdida de la superficie interna, cambios en composición y propiedades del colágeno.

En la caja torácica los cambios están relacionados a osteoporosis, calcificación de cartílagos costales, perdida de tono de la musculatura auxiliar; y en la circulación pulmonar están relacionados con el espesamiento de la capa íntima, perdida de vasos periféricos y cambios arterioscleróticos.

Por otra parte esos cambios anatómicos estructurales producen modificaciones en la función pulmonar que afectan los volúmenes, Salgado, A (1990) indican que la Capacidad vital desciende entre 19 y $35 \mathrm{ml} /$ año a partir de los 35 años y el Volumen espiratorio forzado desciende $30 \mathrm{ml} /$ año en hombres no fumadores. Estos cambios se dan en un contexto ambiental, por lo que la calidad del aire inhalado es importante. Durante un día normal, una persona realiza 25.000 respiraciones e inhala más de 10.000 litros de aire. El aire inhalado está compuesto principalmente por oxigeno y nitrógeno, aunque también contiene pequeñas cantidades de otros gases, contaminantes como bacterias y virus, y muchos agentes contaminantes ambientales como el humo del tabaco y gases de combustión de los automóviles. 
Los pulmones tienen una serie de barreras incorporadas y de defensas para proteger su función; sin embargo, el envejecimiento, la enfermedad y/o una exposición prolongada a contaminantes, pueden degradar esas defensas y el resultado son alteraciones respiratorios agudas o crónicas.

Otros de los cambios a señalar son la disminución del reflejo tusigeno y la disminución de la acción ciliar que contribuyen a un mayor riesgo de aspiración e infección respiratorias.

Los cambios en la función inmunitaria también juegan un papel fundamental con respecto a la afectación pulmonar entre ellos disminución de la eficacia de los cilios que protegen el tubo respiratorio para eliminar los restos de vías aéreas, permitiendo que otros cuerpos extraños lleguen a los pulmones, otros pueden ser disminución de la naturaleza y cantidad de los anticuerpos producidos, disminución de la producción de anticuerpos tras inmunización y el uso de determinados fármacos que puedan suprimir esta función. En las PAM, el declive general de la respuesta inmunitaria da lugar al aumento de susceptibilidad a tuberculosis, neumonía y gripe. El uso de medicamentos como glucocorticoides y antineoplásicos pueden deprimir la respuesta de inmunidad y colocarlos en riesgo de adquirir una infección respiratoria bacteriana o vírica.

\section{LAS ENFERMEDADES RESPIRATORIAS}

Las enfermedades respiratorias (ER) de carácter crónicas son la bronquitis, enfermedad pulmonar obstructiva (EPOC), asma bronquial, bronquiectasias y las agudas son las infecciones respiratorias altas seguido de neumonías y bronquitis. Son consideradas a nivel mundial como una gran carga sanitaria y como las principales causas de discapacidad severa en las PAM; así mismo las infecciones respiratorias agudas (IRAs) constituyen una importante causa de morbimortalidad, en los dos extremos del ciclo vital.

En Argentina, todos los años se verifica un progresivo aumento de los casos de IRAs en la época invernal, asociado a un incremento en la demanda de atención, número de hospitalizaciones y de la mortalidad por causas respiratorias.

Datos Estadísticos del Ministerio de Salud y Ambiente de Santa Cruz para el periodo 2011 a 2015 refieren que la mortalidad por enfermedades respiratorias según grupo etario entre los 65 y 74 años corresponde a más de 40 casos. Datos del 2015 muestran IRAs por departamento geográfico, para el departamento Güer Aike -donde se ubica la ciudad capital Rio Gallegos- le corresponden 5 casos.

\subsection{Enfermedades respiratorias Crónicas}

\subsubsection{EPOC}

Se la define como una ER crónica caracterizada por una limitación al flujo aéreo que no es completamente reversible y se diagnostica mediante una espirometria. Esta limitación es habitualmente progresiva y va asociada a una respuesta inflamatoria de los pulmones frente a gases y partículas nocivas se por espirometria; si es importante destacar que es prevenible y tratable. Las EPOC incluyen bronquitis crónica y enfisema.

En el Estudio de la Carga Mundial de Morbilidad de la OMS (2017) la prevalencia de las EPOC fue de 251 millones de casos, la muerte por esta causa es aproximadamente de 3,17 millones para el año 2015. La incidencia podría aumentar en los próximos años a causa de la mayor prevalencia de tabaquismo y al envejecimiento de la población en muchos países

En Argentina, el primer estudio sobre Prevalencia de EPOC, realizada en 6 aglomerados urbanos de las provincias de Buenos Aires, Santa Fe, Córdoba y Mendoza, entre 2014 Y 
2016, en población $\geq 40$ años, arrojo datos que más de 2,3 millones de argentinos padecen EPOC con elevada tasa de subdiagnóstico y error diagnóstico.

Se considera la cuarta causa de muerte por encima de los 60 años y origina un alto coste sanitario tanto desde el punto de vista económico como de la utilización de recursos médicos.

\subsubsection{Bronquitis crónica.}

Se la diagnostica por presencia de tos y producción de esputos la mayoría de los días durante un mínimo de 3 meses hasta al menos 2 años consecutivos o durante 6 meses a 1 año. La pérdida de elastina produce estrechamiento de los bronquiolos, lo que puede limitar el flujo de aire hacia el exterior del pulmón.

\subsubsection{Enfisema.}

Implica una destrucción permanente de los alveolos, debido a la destrucción irreversible de la elastina, una proteína importante para el mantenimiento de la presión de las paredes alveolares. Se desarrolla normalmente en ancianos con una larga historia de tabaquismo, se estima que es responsable aproximadamente en el $90 \%$ por tabaquismo en los diagnosticados con EPOC.

\subsubsection{Asma}

Se caracteriza por obstrucción del flujo de aire normalmente reversible, inflamación de las vías aéreas, aumento de la producción y secreción de moco y aumento de la sensibilidad de las vías aéreas a diversos estímulos.

El asma en las PAM no diagnosticadas y sin tratar reduce la calidad de vida y contribuye a su debilidad, es un problema de salud poco reconocido en las PAM, que conduce al deterioro de la función pulmonar, con el consecuente impacto en la calidad de vida, que hasta la fecha ha sido poco estudiada, subdiagnosticada y subtratada según Yáñez, A., \& Bueno, C. (2016).

Según la Organización Mundial de la salud el año 2015 se registró 383.000 muertes en el mundo y en el año 2017, 235 millones de personas la padecían en si bien es la enfermedad no transmisible más frecuente en niños la mayoría de las muertes corresponden a adultos de edad avanzada. En Argentina no se evidencian datos específicos sobre la prevalencia de asma en la población de adultos mayores.

Si bien en nuestro país, el Programa Nacional de Prevención y control de Enfermedades Respiratorias Crónicas, apunta a contribuir a la reducción de la morbilidad y mortalidad, priorizando asma y EPOC en la población adulta, sigue siendo un desafío fomentar la investigación en asma en el adulto mayor, utilizando el conocimiento existente para mejorar el diagnóstico, y los diagnósticos diferenciales, así como educar al paciente, desarrollar un enfoque terapéutico seguro y eficaz, controlar la enfermedad y, finalmente, proporcionar una mejor calidad de vida.

\subsection{Infecciones Respiratorias Agudas (IRAs)}

Las IRAs constituyen un grupo de enfermedades causadas por diferentes virus y bacterias, comienzan de forma repentina y duran menos de 2 semanas, son las más frecuentes en el mundo y representan un importante tema de salud pública en nuestro país. La mayoría de estas infecciones como el resfriado común son leves, pero dependiendo del estado general de la persona pueden complicarse y llegar a amenazar la vida, como en el caso de las neumonías.

En 2015 se registraron 56901 muertes por enfermedades del sistema respiratorio en Argentina, lo que representó el $17,07 \%$ del total de muertes por cualquier causa y fue la tercera causa de muerte detrás de las enfermedades del sistema circulatorio y los tumores. El $85 \%$ de las defunciones por enfermedades respiratorias se concentraron en tres grupos de 
causas: $48,85 \%$ muertes por Neumonía, $22,89 \%$ por otras enfermedades del sistema respiratorio y 13,49\% por enfermedades crónicas de las vías respiratorias inferiores. El análisis de la mortalidad evidenció un aumento del número de fallecidos con la edad, ocupando el mayor porcentaje de defunciones personas de 65 y más años, con un $85.5 \%$. El riesgo se acentúa en la población de 80 años y en adelante sobre todo en los masculinos por muerte de causas respiratorias.

\subsubsection{Resfrío}

Es una enfermedad benigna, autolimitada, de corta duración y sus complicaciones son poco frecuentes, se puede considerar como la infección más frecuente de la vía aérea tanto en niños como en adultos. La etiología es viral, pudiendo se producida por amplios virus, son la presentación más frecuente de infecciones de la vía aérea superior. Los rinovirus son responsables de la gran mayoría de los episodios de resfrió común, su periodo de incubación es corto, de 1 a 6 días con promedio de dos.

\subsubsection{Gripe}

La gripe es una infección vírica aguda del tracto respiratorio que afecta a todos los grupos de edad. Sin embargo, son las personas mayores de 65 años o con enfermedades subyacentes los que sufren una mayor mortalidad por cuadros gripales, casi siempre debido a una neumonía bacteriana secundaria o a insuficiencia cardiaca. El virus de la influenza A y el B son las formas responsables de la mayor parte de los cuadros clínicos. El virus influenza A, y en menor medida el virus influenza $\mathrm{B}$, es antigénicamente muy lábil, y todos los años sufre cambios en sus proteínas de superficie, dependiendo de la profundidad de estos cambios antigénicos, aparecerán brotes epidémicos o verdaderas pandemias.

La OMS recomienda la vacunación anual en: embarazadas en cualquier fase de la gestación; niños de 6 meses a 5 años; mayores de 65 años; pacientes con enfermedades médicas crónicas; profesionales sanitarios. La vacuna antigripal puede evitar la aparición de neumonía adquirida en la comunidad (NAC) en pacientes de alto riesgo.

En Argentina existe la Ley $\mathrm{n}^{\circ} 27.491$ de Control de enfermedades prevenibles por vacunación, promulgada en enero 2019 que dispone que el Calendario Nacional de Vacunas es de carácter obligatorio, son gratuitas y se aplican en vacunatorios, centros de salud, hospitales públicos y en organizaciones que adhieren a las campañas nacionales, tal es el caso de la Unidad académica Rio Gallegos de la Universidad Nacional de la Patagonia Austral

\subsubsection{Neumonía}

Es definida por la Organización Mundial de la Salud (OMS), como un tipo de infección respiratoria aguda que afecta a los alveolos produciendo pus y líquido, lo que hace dolorosa la respiración y limita la absorción de oxígeno. La neumonía puede ser causada de virus, bacteria y hongos. Las infecciones virales por influenza A y B; parainfluenza y adenovirus son responsables de hasta el $15 \%$ de las NAC, casi siempre en forma de epidemias.

La NAC presenta variaciones estacionales, con mayor énfasis durante el invierno, y es más frecuente en hombres que en mujeres; es una causa frecuente de morbilidad y mortalidad mundialmente. En personas mayores de 60 años, la incidencia es de 2 a 6 veces superior que en el resto de la población adulta. En Argentina extrapolando los valores de incidencia descriptos en un estudio local realizado en la Ciudad de General Roca, se estima que anualmente serian más de 150 mil los casos por neumonía en personas mayores de 18 años y 
los datos llamativos radican en la mortalidad de los mayores de 65 años, a los 14 días de internarse.

Un aspecto importante en la prevención de la NAC es el adecuado control de las enfermedades crónicas subyacentes, evitando, en la medida de lo posible tratamientos que alteren los mecanismos defensivos. El abandono del hábito tabáquico y del consumo excesivo de alcohol, también son dos importantes medidas preventivas y recibir la vacuna es la mejor manera de prevenir la enfermedad.

Dos vacunas previenen la meningitis, la bacteriemia y la neumonía, ellas son la conjugada de 13 serotipos (VCN13) y la polisacárida de 23 serotipos (VPN23), ambas incluidas en el calendario nacional de vacunación.

\subsection{Otras enfermedades respiratorias}

\subsubsection{Tuberculosis}

Existe un aumento preocupante de la tuberculosis, la resistencia a los medicamentos y la pobreza son ejes a tener en cuenta al momento de analizar los datos. En el año 2018 Según la OMS respecto a Tuberculosis (TBC), 10 millones de personas la padecían y 1,5 millones desencadenaron en la muerte (entre ellos, 251. 000 personas con VIH). Se calcula que a nivel mundial el 1,6\% de los casos de tuberculosis son atribuibles al tabaquismo.

La TB en ancianos puede ser la reactivación de una enfermedad antigua o una infección nueva debido a la exposición a un individuo infectado. Entre los factores de riego para desarrollar o reactivar la TB se encuentran entre, vivir en una residencia, diabetes mellitus, uso de fármacos inmunosupresores, tumor maligno, desnutrición, insuficiencia renal.

En Argentina, durante el año 2017 se notificaron 11.659 casos de TBC, incluyendo casos nuevos, recaídas, con antecedente de tratamientos previos y aquellos casos sin información respecto a tratamientos anteriores, resultando así una tasa de 26,5 casos por 100.000 habitantes. En cuanto a la distribución por edad y género, la mayor diferencia de tasas se observó en el grupo de adultos mayores de 60 a 64 años, siendo la tasa en varones más del doble que en las mujeres, 36,5 y 16,9 por 100,000 habitantes respectivamente. Un dato a tener en cuenta es que la mortalidad por Tuberculosis represento un $35,4 \%$ en adultos mayores de 65 años.

\subsubsection{Cáncer}

En Argentina el cáncer constituye la segunda causa de muerte de acuerdo al Ministerio de Salud (2016), concentrada en aproximadamente la quinta parte de todas las defunciones y representa una de las cuatro enfermedades crónicas no transmisibles más relevantes.

Según lo expresado en el boletín epidemiológico del Ministerio de Salud, (2018). La incidencia del cáncer ocurre predominantemente en los adultos mayores y teniendo en cuenta la el aumento demográfico sobre la población nombrada estiman que para el año 2035 se duplicará tanto la incidencia como la mortalidad por cáncer en Argentina.

\section{TRABAJO DE CAMPO}

\subsection{Delimitación Territorial}

El barrio Belgrano se encuentra posicionado geográficamente a un kilometro al sudeste del centro de Rio Gallegos, en la Provincia de Santa Cruz. Durante el siglo XX existieron flujos 
migratorios procedentes de la Patagonia Chilena, en Rio Gallegos gran parte de esta población conformo al barrio Belgrano y su proceso histórico de ocupación. En la ciudad de Rio Gallegos se desconoce la prevalencia de Enfermedades Respiratorias Agudas y Crónicas en los Adultos Mayores del barrio Belgrano. El vertiginoso cambio demográfico para Santa Cruz produce quizás una demanda de estudios desde el punto de vista sociosanitario.

Norambuena, M. (2015). Expresan que durante el siglo XX, el territorio de la actual Provincia de Santa Cruz ha recibido flujos migratorios procedentes de países limítrofes como Chile y de otras provincias de Argentina, y que particularmente en el período comprendido entre las décadas de 1960 y 1980, esta oleada migratoria hacia la Patagonia Argentina, pudo estar asociada no sólo a dificultades económicas y sociales, sino a la restricción de las libertades políticas que alcanzó su máxima expresión con la instalación de la dictadura.

El Decreto No 510/77 del Departamento Ejecutivo de la Municipalidad de Río Gallegos, suscribe la delimitación del barrio Belgrano indicando las calles. Frías (2007) destaca que dado el proceso histórico de ocupación, este barrio se fue diferenciando en dos sectores: el Belgrano Viejo y el Belgrano Nuevo, cada uno con identidad propia, denominados con esos nombres por los mismos vecinos, y que se refrenda con el Decreto municipal No 1905/91. Así mismo destaca que el barrio Belgrano Nuevo, es denominado posteriormente por la Municipalidad de Río Gallegos, con el nombre Santa María de Belén.

El barrio y particularmente el Centro de jubilados cuenta con establecimientos de salud municipales y provinciales como el Centro integrador (CENIN) $N^{\circ} 8$ Ex Tiro Federal, y el Centro Integrador Comunitario (CIC) Santa María de Belén.

\subsubsection{Un acercamiento a la Creación del Centro de Jubilados}

Es interesante destacar que el acercamiento a la población en estudio permitió conocer la fortaleza, el sentido de identidad y la importancia que le dan las PAM al Centro de jubilados. Al recabar datos de los orígenes del mismo, la actual presidente Míguela Artaza se remonta a recordar a la primer presidenta del centro la señora Marta Batello y a los primeros encuentros en un gimnasio municipal y a las primeras actividades compartidas, hasta que inician los trámites administrativos para la creación formal y la asignación de un nombre, surge así la denominación Encuentro de Amigos y se obtiene la personería jurídica en el año 2012.

Actualmente la comisión está compuesta por trece personas. Manifiesta su presidenta que la realización de las actividades que llevan a cabo son de carácter solidaria, que les reconforta el alma y les hace sentir realizados con proyectos, con un deseo a futuro de tener el espacio propio, para poder brindarle a los socios las distintas actividades socio preventivas, y brindar el espacio para reuniones no solo añadida a festejos si no para la contención y apoyar a los pares y familiares. Es importante destacar aquí la importancia de la participación comunitaria de los actores del centro de jubilados, se sienten parte de y generan desde la simplicidad de ser humanos y desde su negación a permanecer en condición de pasivos, reconociéndose como sujetos socialmente vivos. De esta manera resaltan la importancia de los lazos sociales, porque a través de ellos pueden identificar la necesidad de ayuda de los vecinos adultos mayores que concurren al centro de jubilados. Con esta visión de participación comunitaria los equipos de profesionales pueden transformar o abordar las realidades en todos sus contextos, incorporando valores y costumbres de los actores, así las Intervenciones Comunitarias son medios, estrategias, oportunidades y forma de creación de espacios para el encuentro, la sensibilización, la promoción del apoyo social y el intercambio reciproco intencionado, comprometido y voluntario de recursos, aprendizajes, ideas y valores encaminados a producir la construcción de sociedades más justas que integren a las PAM. 


\subsection{Análisis de Datos}

\subsubsection{Materiales y Métodos}

La metodología utilizada se asienta en un cuestionario Ad Hoc de construcción propia, del tipo semiestructurado, aplicado de modo individual a las fuentes primarias: las PAM que asisten al Centro de jubilados Encuentro de Amigos del Barrio Belgrano de Río Gallegos, Sta Cruz, 2019.

Las variables en estudio se basaron en los ejes: sociodemográficos, morbilidad y en particular, enfermedades respiratorias, factores de riesgo y prevención. Este ultimo eje relacionado a la prevención por vacunación, lavado de manos, ventilación del hogar y hábitos tóxicos. El estudio ha sido cuanti-cuali descriptivo de corte transversal, y se ha utilizado INFOSTAT como herramienta para tratar los datos.

\subsubsection{Resultados}

\section{Gráfico $\mathrm{N}^{\mathrm{o}} 1$}

Distribución por sexo de PAM en el Centro de Jubilados Encuentro de Amigos, Barrio Belgrano, Río Gallegos, Argentina, 2019. N=57. Sexo 65\% (M), 35\% (H)

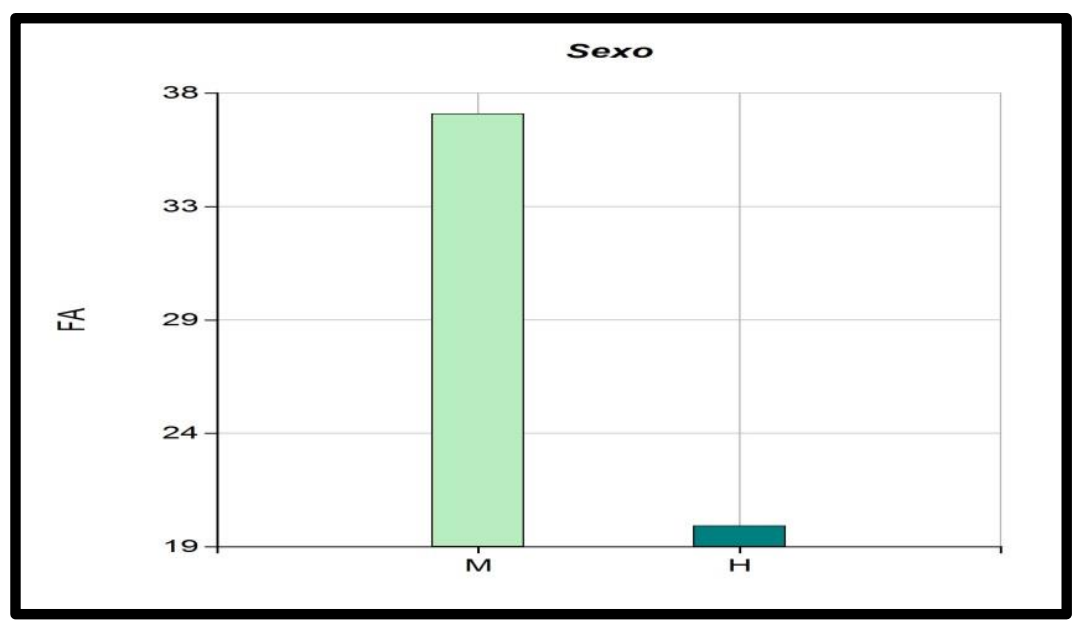

\section{Grafico $\mathrm{N}^{\mathrm{o}} 2$}

Distribución por categoría etaria, de PAM en el Centro de Jubilados Encuentro de Amigos, Barrio Belgrano, Río Gallegos, Argentina, 2019. N=57.

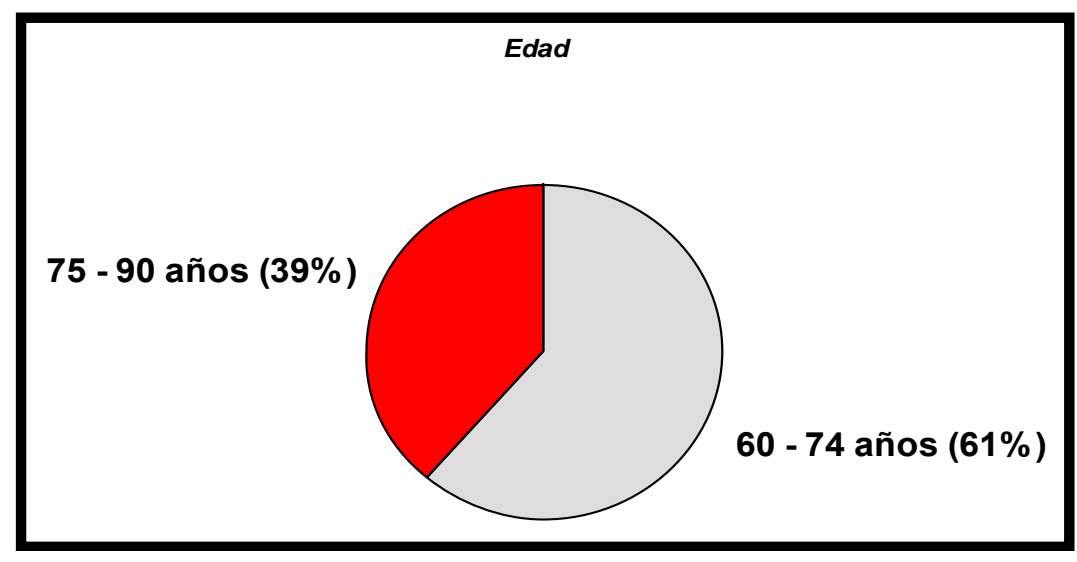




\section{Grafico $N^{\circ} 3$}

Distribución por nivel de educación, de PAM, en el Centro de Jubilados Encuentro de Amigos, Barrio Belgrano, Río Gallegos, Argentina, 2019. N=57. $49 \%$ con primaria incompleta, $44 \%$ con secundaria incompleta, $5 \%$ con secundario completo y $2 \%$ con nivel superior.

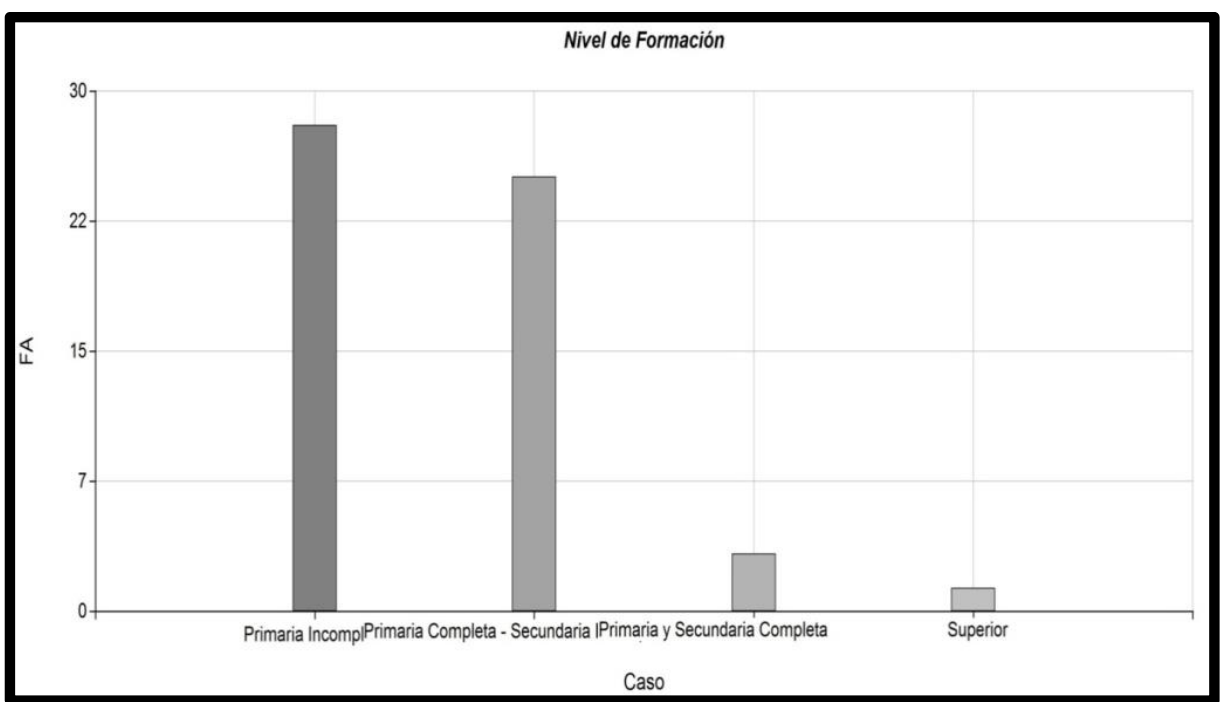

\section{Grafico $\mathrm{N}^{\circ} 4$}

Condición del estado convivencial de las PAM en el Centro de Jubilados Encuentro de Amigos, Barrio Belgrano, Río Gallegos, Argentina, 2019. N=57.

El $65 \%$ de los adultos mayores se encuentra en compañía.

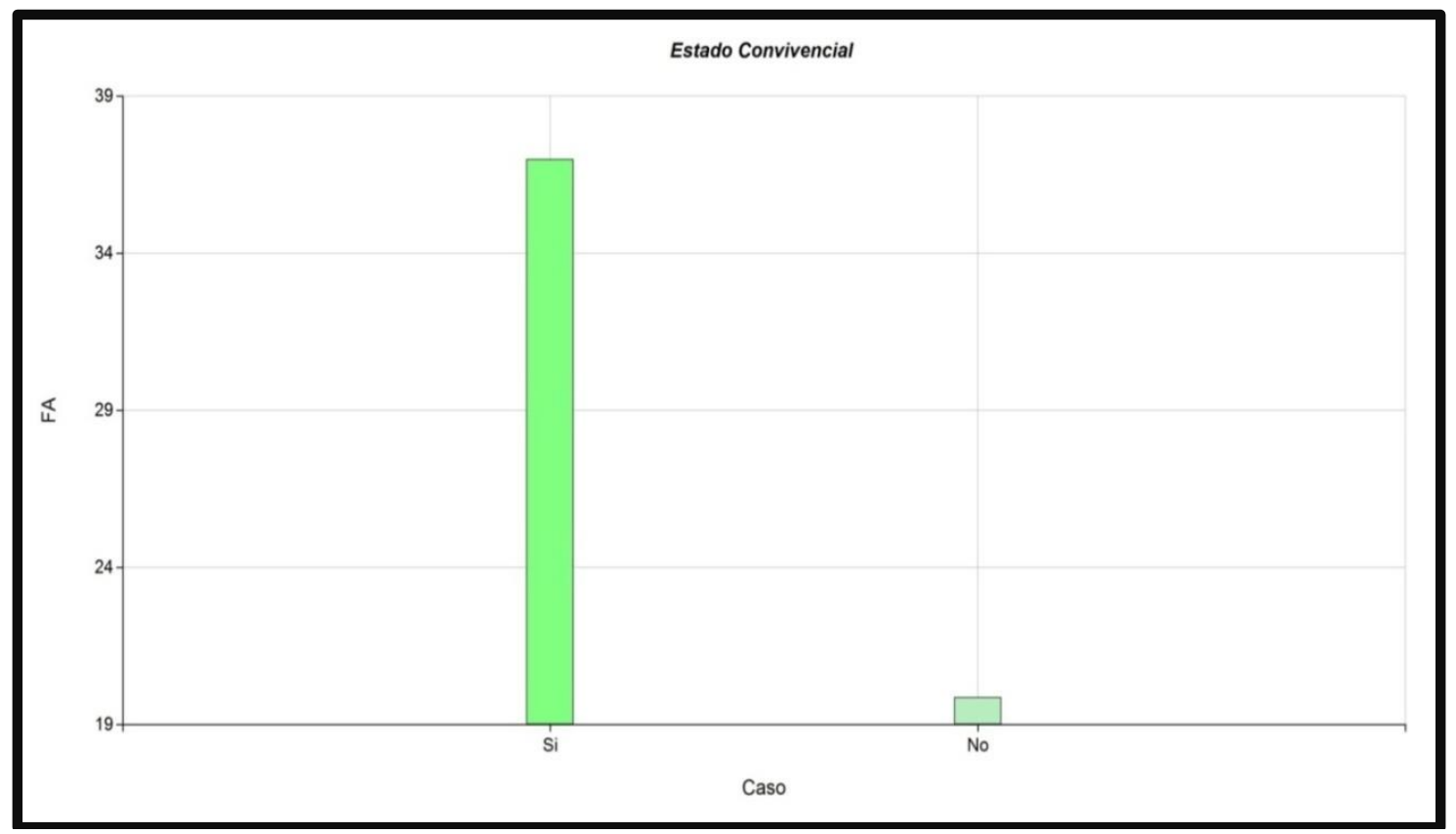


Grafico No 5 (a)

Distribución por presencia de alteraciones/enfermedades respiratorias en PAM del Centro de Jubilados Encuentro de Amigos, Barrio Belgrano, Río Gallegos, Argentina, 2019. N=57.

E1 79\% manifestó no haber tenido episodios de disfunción respiratoria en su vida.

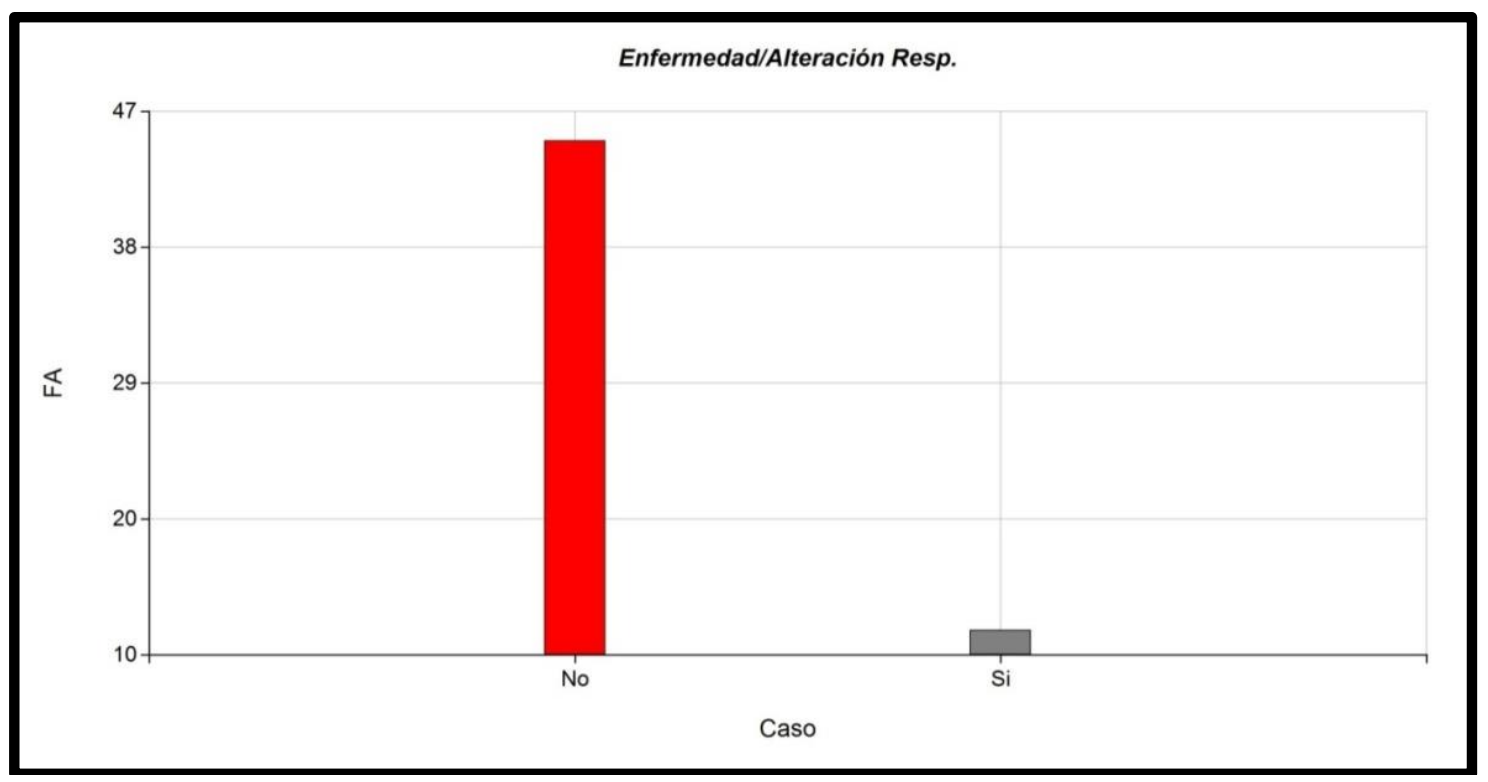

\section{Grafico $N^{\circ} 5$ (b)}

Distribución por tipo de enfermedades/alteraciones respiratorias identificadas en PAM del Centro de Jubilados Encuentro de Amigos, Barrio Belgrano, Río Gallegos, Argentina, 2019.

$$
\mathrm{N}=57 \text {. }
$$

El $13 \%$ de los afectados presentaron episodios de bronquitis aguda, el $4 \%$ neumonía, otro 4\% asma y también un $4 \%$ tienen diagnóstico de Epoc. Se contabilizó un único caso aislado de alteración respiratoria aguda junto con una enfermedad respiratoria crónica, y fue sobre el sexo mujer (bronquitis aguda y asma).

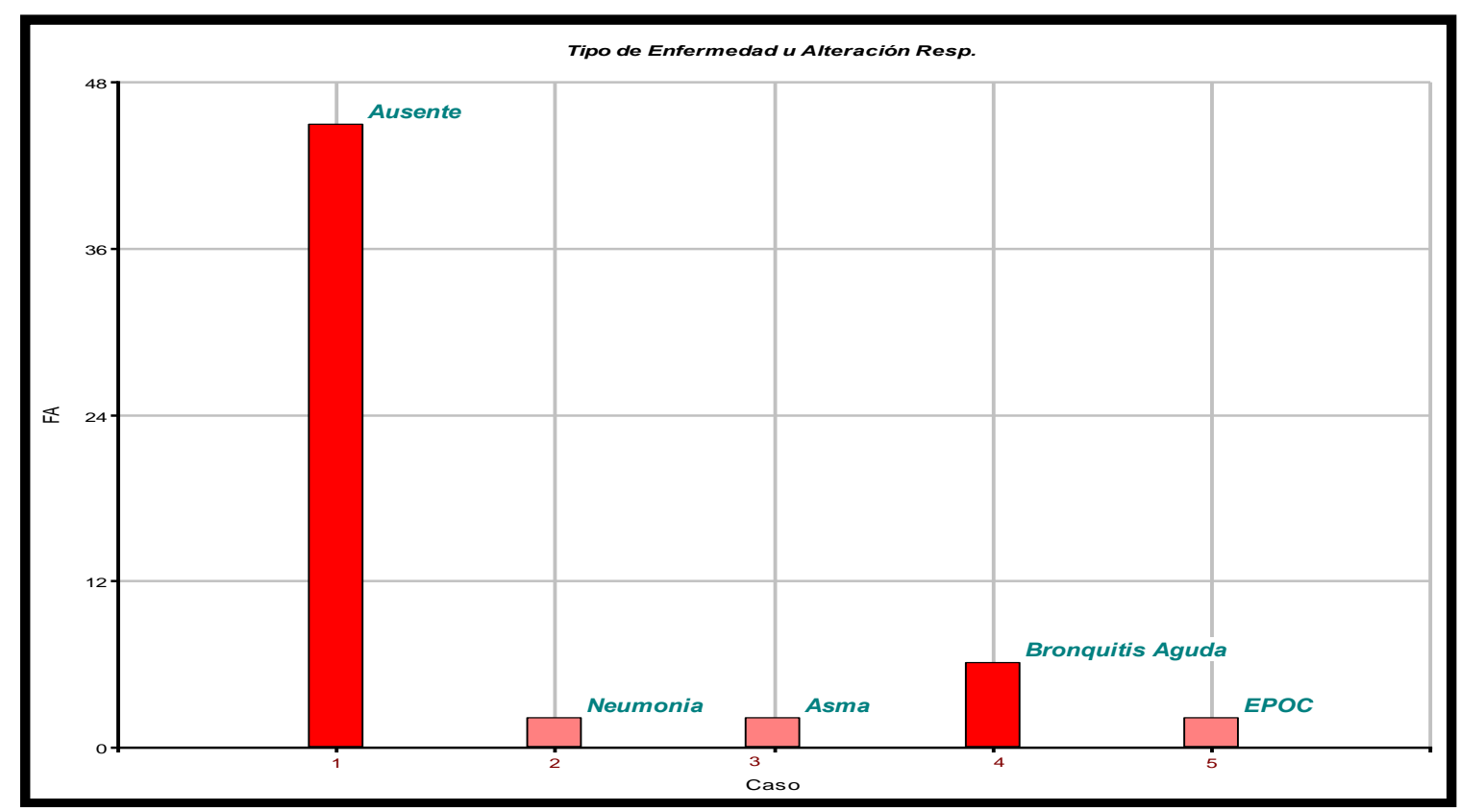




\section{Grafico $\mathrm{N}^{\mathrm{o}} 6$}

Distribución de la cantidad de episodios/ anual de gripe en las PAM del Centro de Jubilados

Encuentro de Amigos, Barrio Belgrano, Río Gallegos, Argentina, 2019. N=57.

$47 \%$ sin episodios, $33 \%$ una vez al año, $12 \%$ dos veces y un $7 \%$ con más de tres al año.

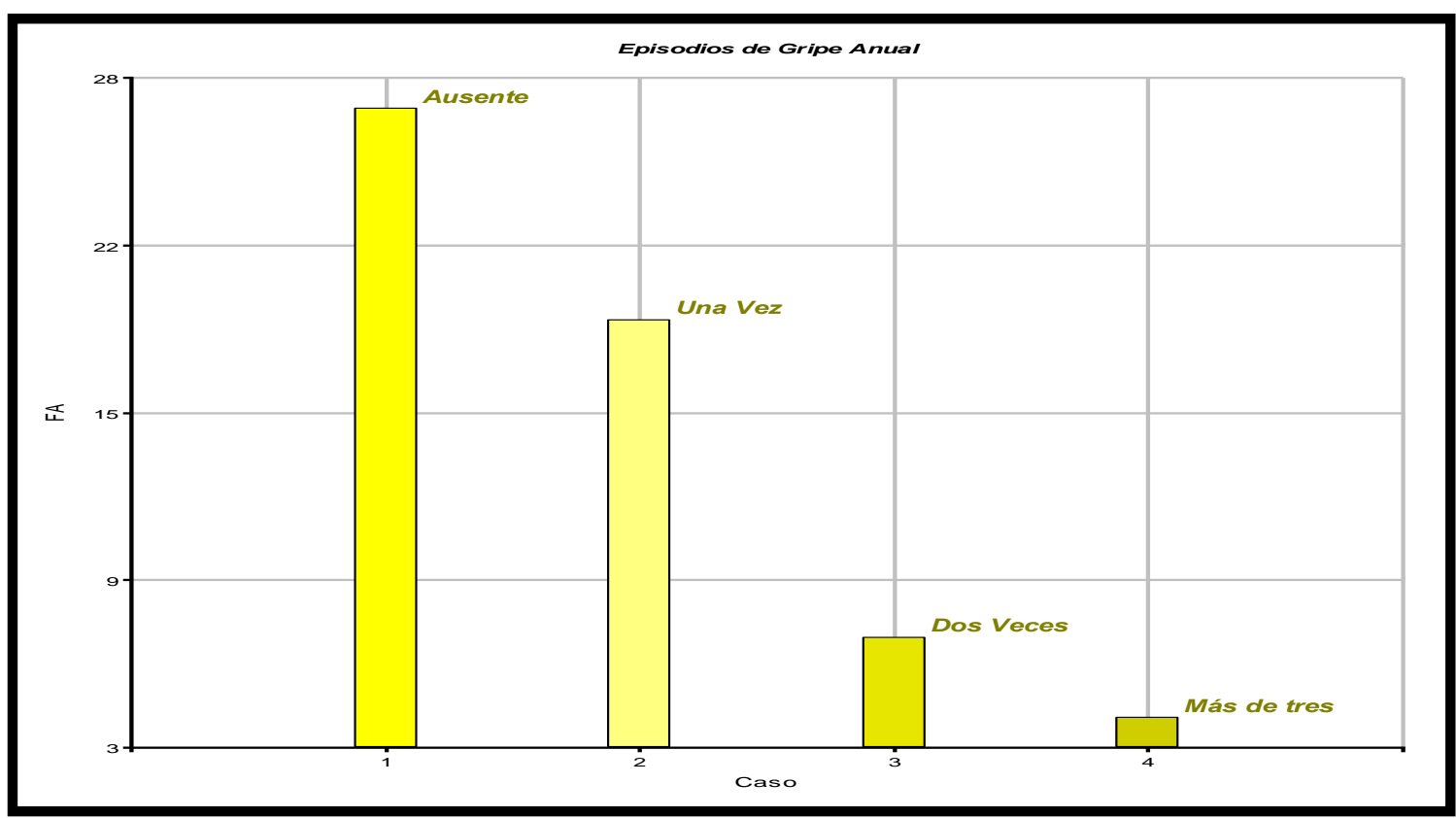

\section{Grafico $\mathrm{N}^{\mathrm{o}} 7$}

Frecuencia estacional de afecciones respiratorias en PAM del Centro de Jubilados Encuentro de Amigos, Barrio Belgrano, Río Gallegos, Argentina, 2019. N=57. $82 \%$ en invierno, un $7 \%$ en verano, $5 \%$ en otoño y en primavera $5 \%$.

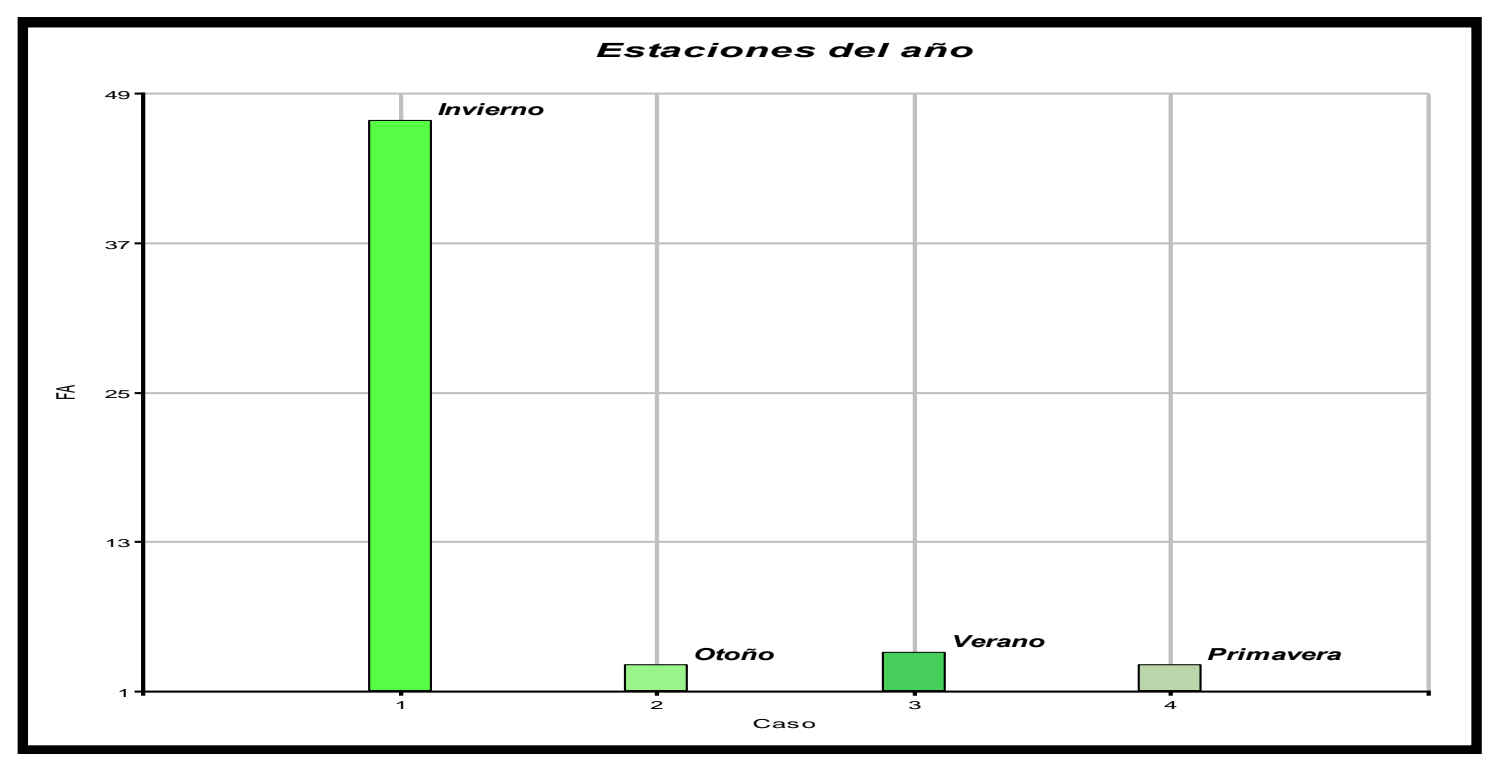




\section{Grafico $\mathrm{N}^{\mathrm{o}} 8$}

Distribución de la presencia de automedicación de ATB en las PAM del Centro de Jubilados Encuentro de Amigos, Barrio Belgrano, Río Gallegos, Argentina, 2019. N=57.

El 93\% declaró no consumir antibióticos sin indicación médica.

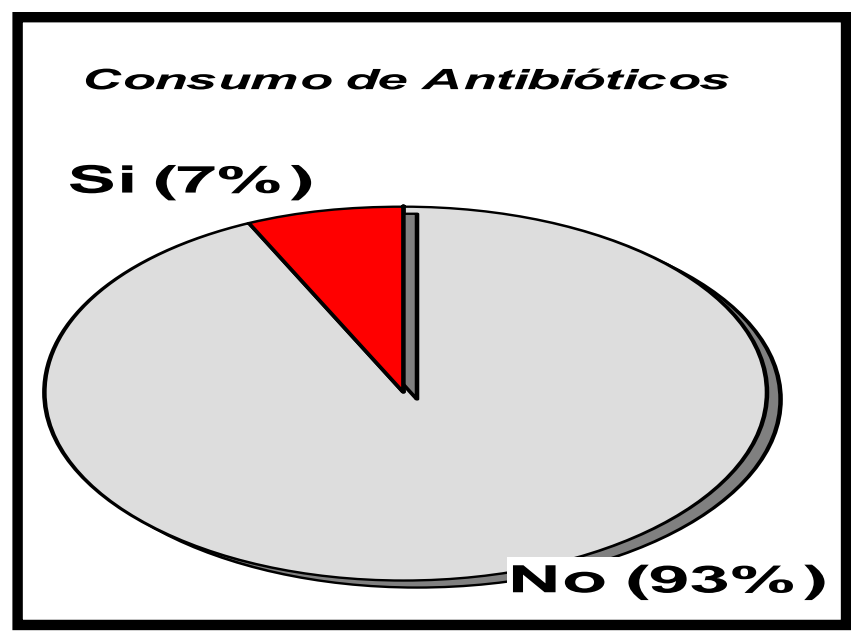

Grafico $N^{\circ} 9$

Frecuencia de asistencia al control médico en las PAM del Centro de Jubilados Encuentro de Amigos, Barrio Belgrano, Río Gallegos, Argentina, 2019. N=57.

$42 \%$ manifestó hacerlo una vez al año, el 14\% dos veces, tres veces al año 14\%, un 19\% contestó otra frecuencia, y un $11 \%$ dijo no asistir a controles.

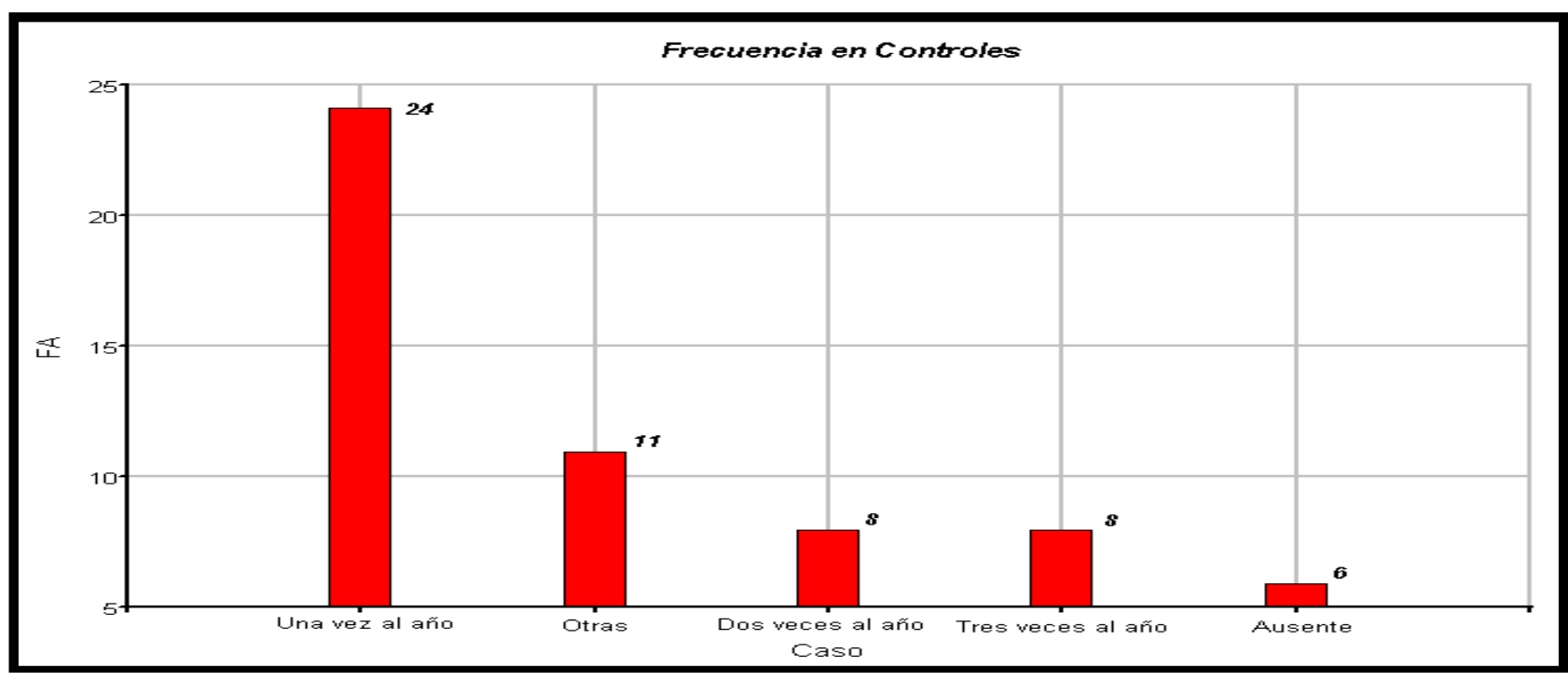




\section{Grafico $\mathrm{N}^{\mathrm{o}} 10$}

Distribución según conocimiento de vacunas asociadas a problemas respiratorios, en las PAM del Centro de Jubilados Encuentro de Amigos, Barrio Belgrano, Río Gallegos, Argentina, 2019. $\mathrm{N}=57$.

$68 \%$ no conoce las vacunas, $23 \%$ dijo conocer la vacuna antigripal anual, sólo con un $9 \%$ dijo tener conocimiento sobre la vacuna antigripal y antineumococica.

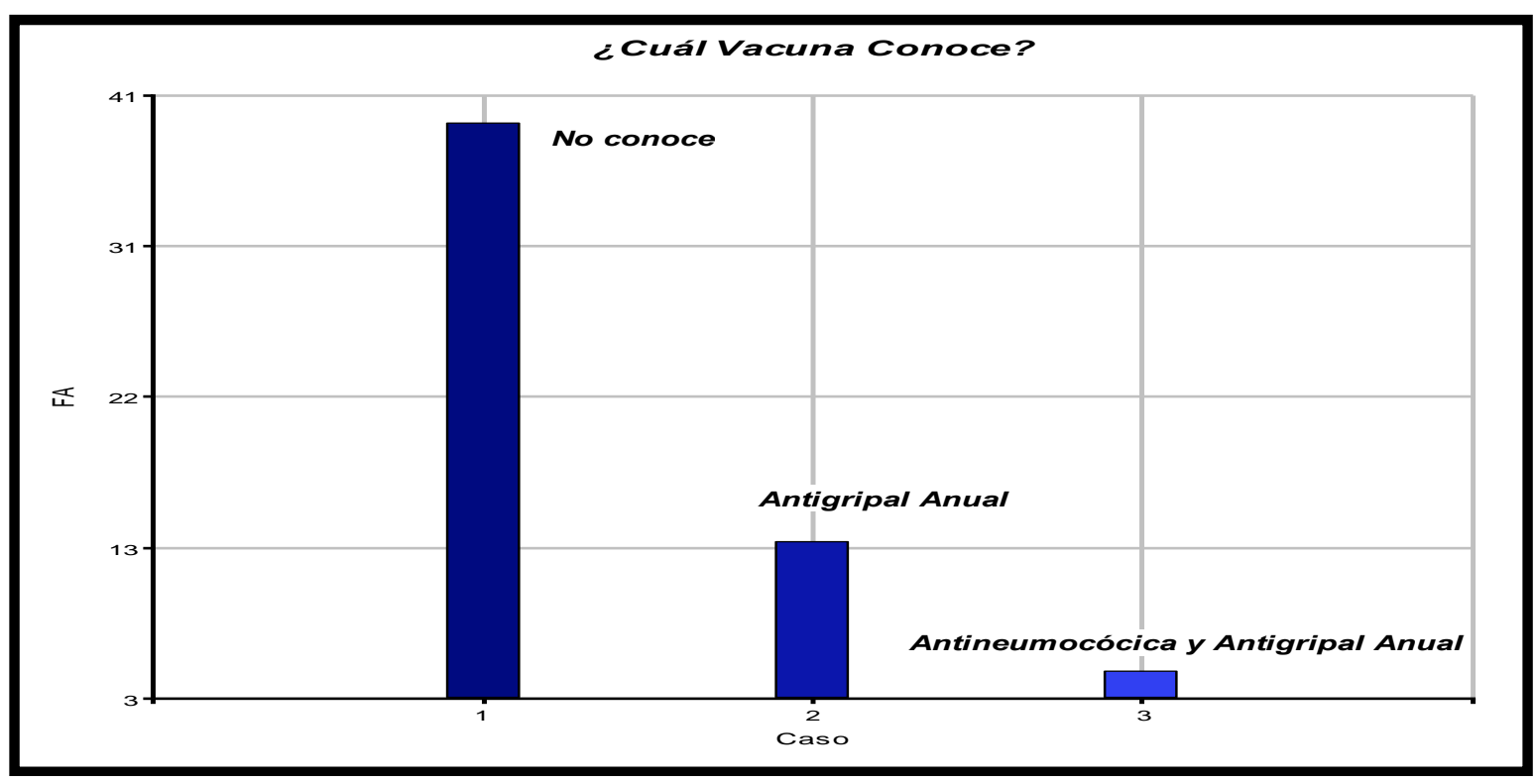

Grafico $N^{\circ} 11$

Distribución según la aplicación de vacuna antigripal anual en PAM del Centro de Jubilados Encuentro de Amigos, Barrio Belgrano, Río Gallegos, Argentina, 2019. N=57. El 56\% no se encuentra vacunado.

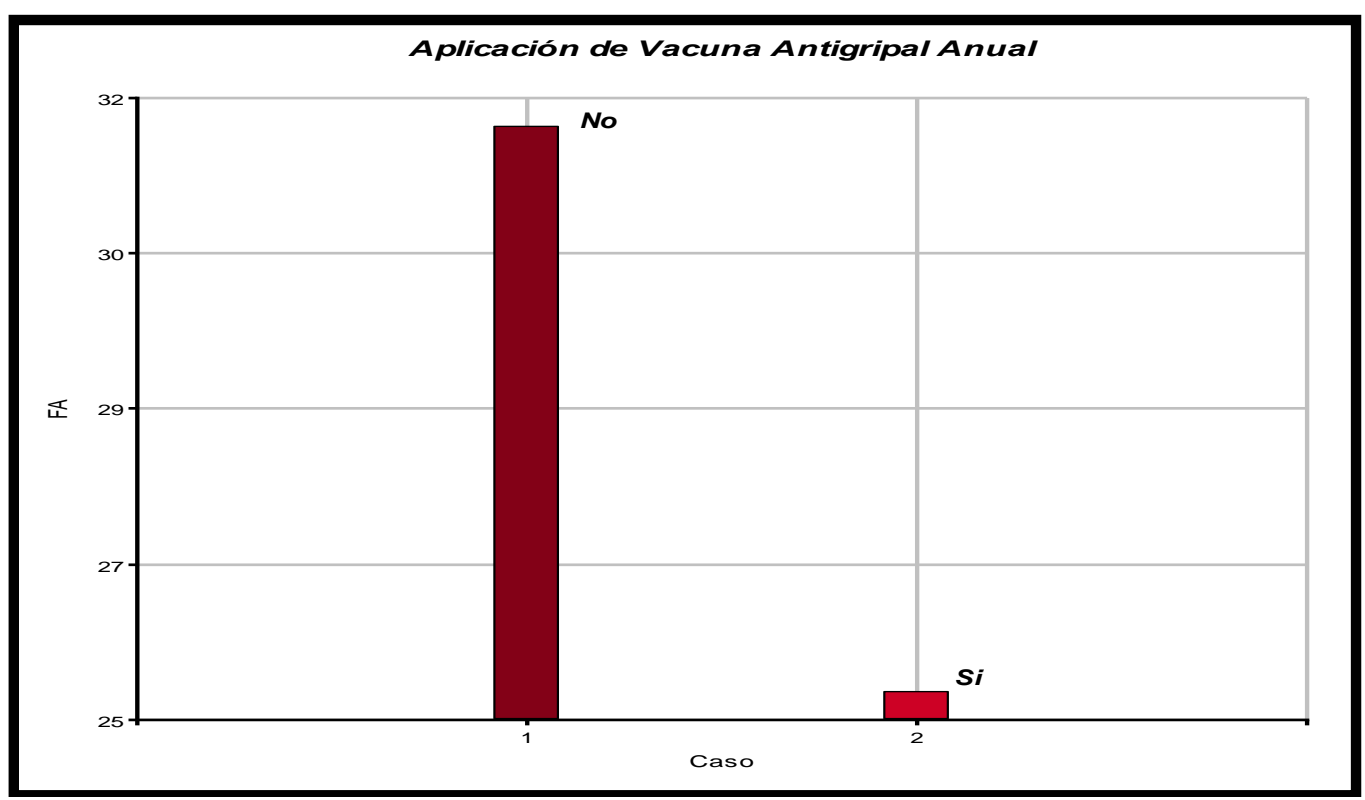




\section{Grafico $N^{\circ} 12$}

Distribución según la aplicación de vacuna antineumococica en PAM del Centro de Jubilados Encuentro de Amigos, Barrio Belgrano, Río Gallegos, Argentina, 2019. $\mathrm{N}=57$.

Un $75 \%$ dijo no habérsela aplicado para este periodo anual.

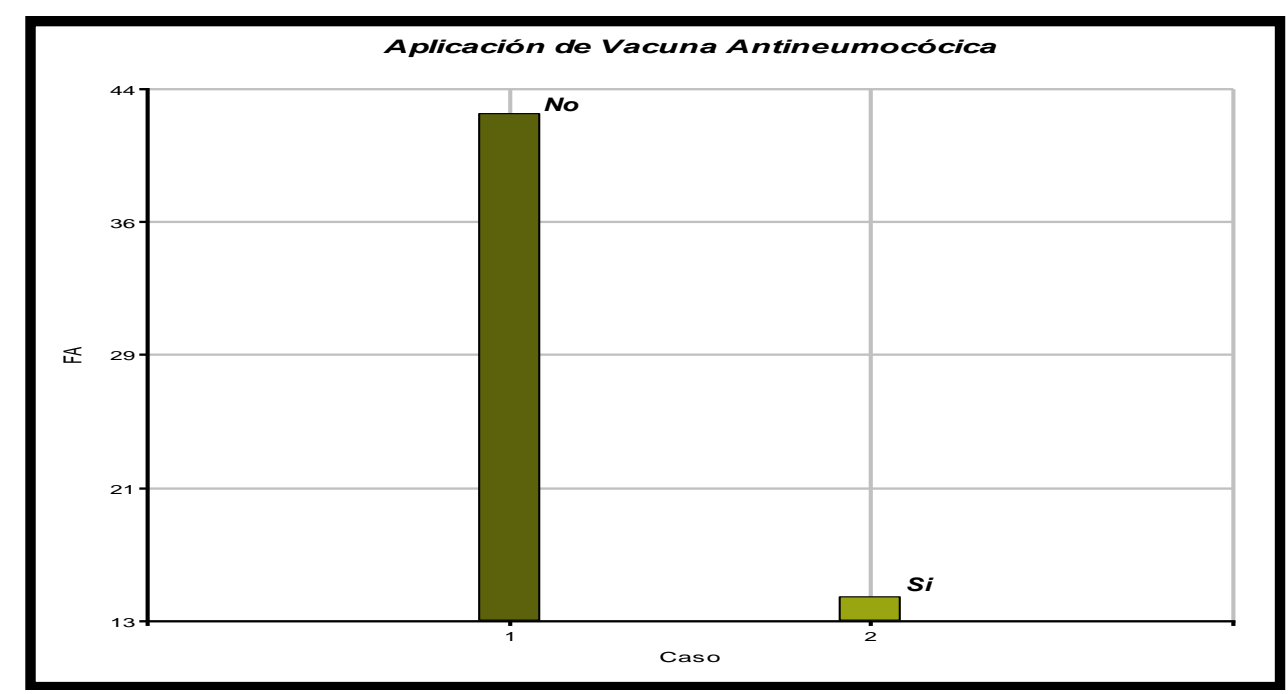

Grafico $\mathrm{N}^{\mathrm{o}} 13$

Distribución según conocimiento de la higiene de manos en PAM del Centro de Jubilados Encuentro de Amigos, Barrio Belgrano, Río Gallegos, Argentina, 2019. N=57. 96\% reconoce la importancia.

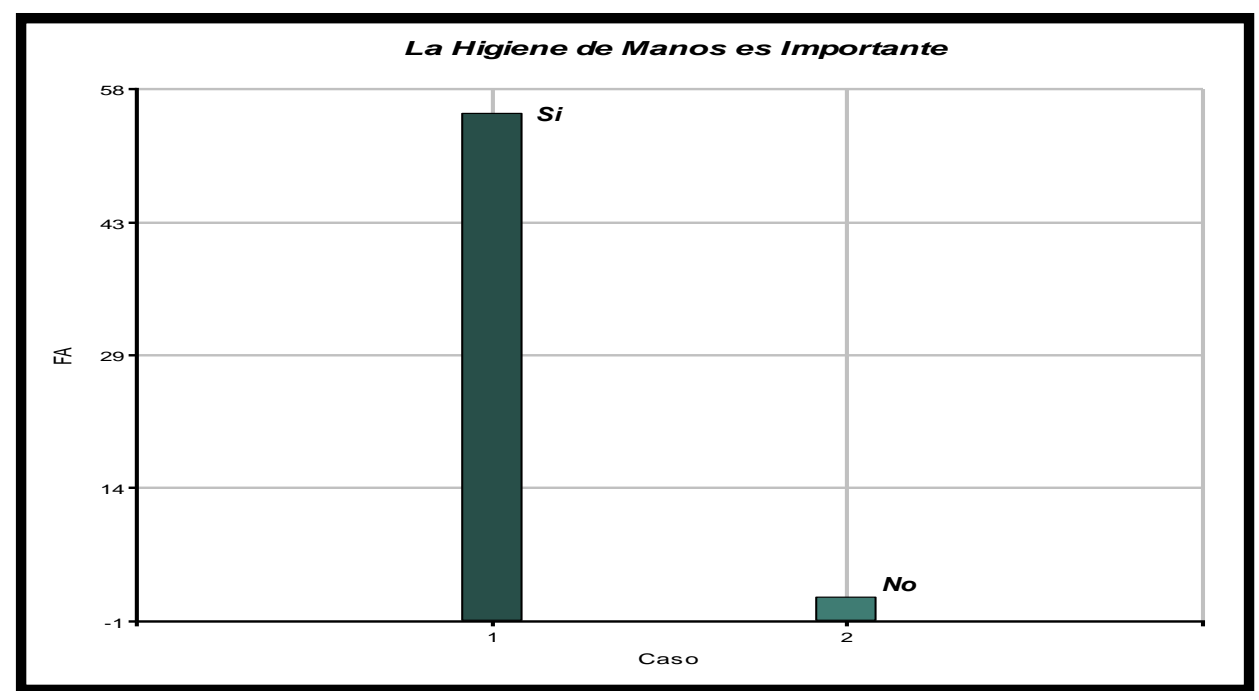




\section{Grafico $\mathrm{N}^{\circ} 14$}

Distribución por hábitos tóxicos en las PAM del Centro de Jubilados Encuentro de Amigos,

Barrio Belgrano, Río Gallegos, Argentina, 2019. N=57.

El 93\% de la población de estudio no fuma.

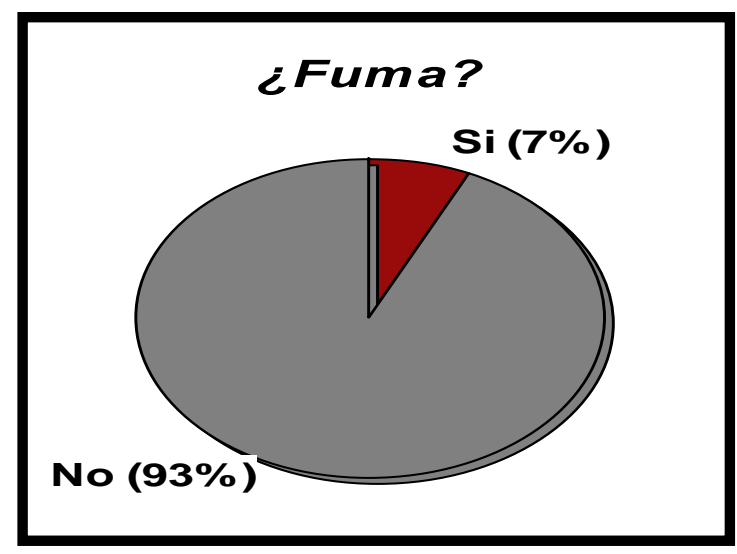

Grafico $\mathrm{N}^{\mathrm{o}}$ 15-Tabla de contingencia

Distribución por aplicación de vacuna antigripal anual según sexo de PAM del Centro de Jubilados Encuentro de Amigos, Barrio Belgrano, Río Gallegos, Argentina, 2019. N=57.

El $50 \%$ de los varones y el $40 \%$ de las mujeres recibieron la vacuna anual.

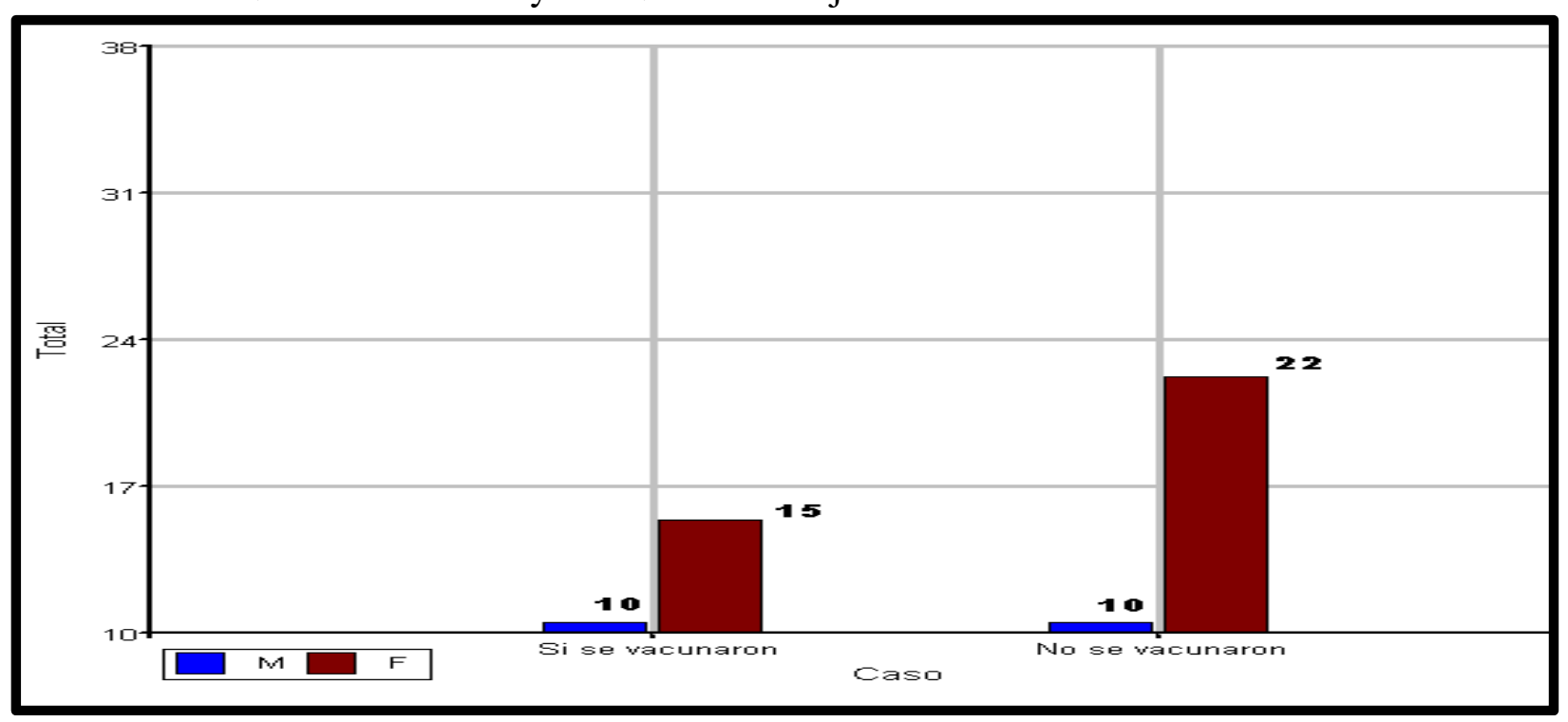


Grafico $\mathrm{N}^{\mathrm{o}}$ 16-Tabla de contingencia

Distribución por aplicación de vacuna antineumocócica según sexo de PAM del Centro de Jubilados Encuentro de Amigos, Barrio Belgrano, Río Gallegos, Argentina, 2019. N=57. Un 25\% de los Varones se vacunaron y ente las Mujeres se mantiene aproximadamente esa misma proporción $(24.32 \%)$.

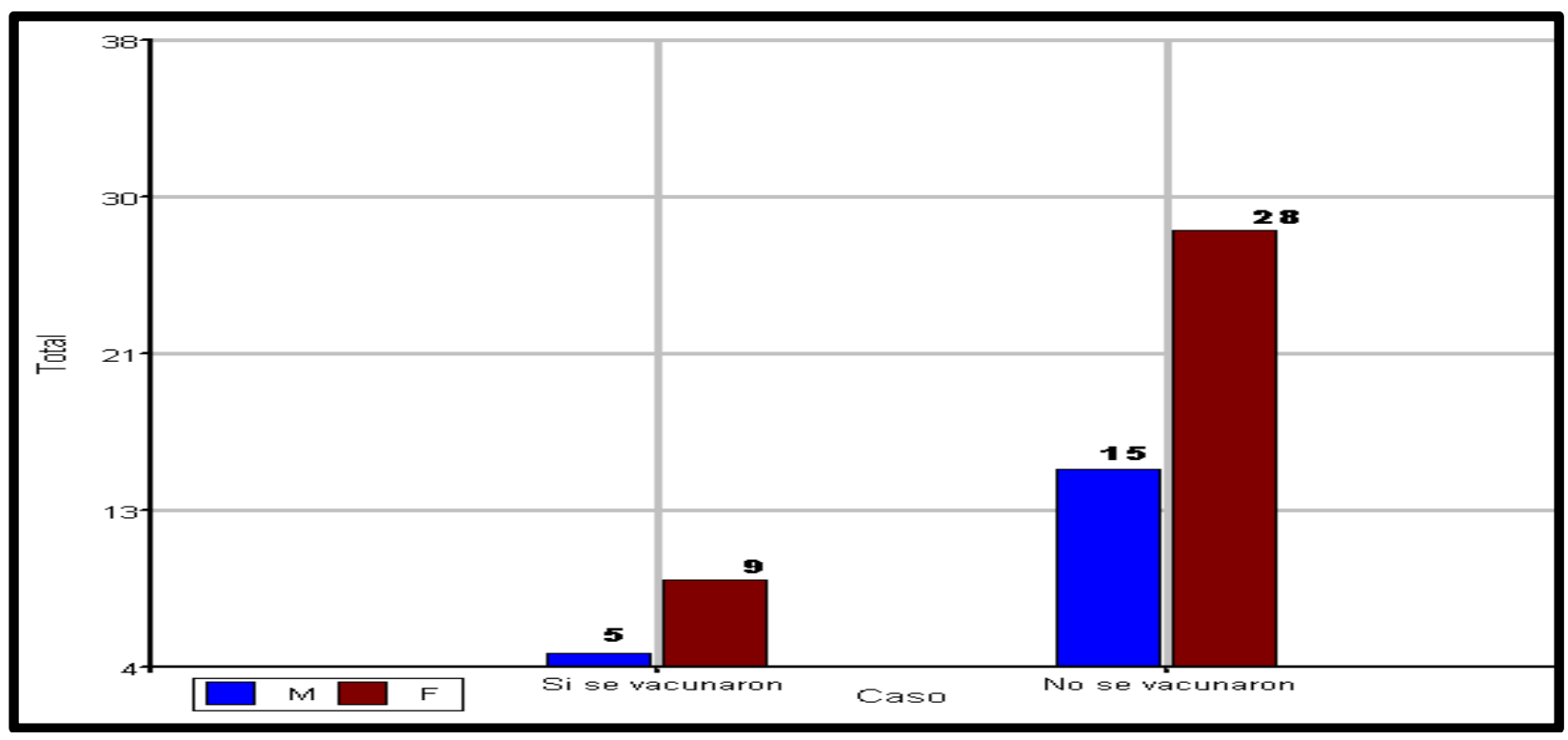

Tabla 1.- Tabla de Frecuencias de las Variables de estudio

\begin{tabular}{|c|c|c|c|c|c|c|c|}
\hline Variable & Categ. & $\begin{array}{l}\mathrm{F} \\
\mathrm{A}\end{array}$ & FR & Variable & Categ & FA & $\mathrm{FR}$ \\
\hline \multirow[t]{2}{*}{ Sexo } & M & 37 & $\begin{array}{c}0,6 \\
5\end{array}$ & $\begin{array}{r}\text { Consumo de Antibióticos sin } \\
\text { Indicación Médica }\end{array}$ & 1 & 53 & 0,93 \\
\hline & $\mathrm{H}$ & 20 & $\begin{array}{c}0,3 \\
5\end{array}$ & & 0 & 4 & 0,07 \\
\hline \multirow[t]{2}{*}{ Edad } & 0 & 35 & $\begin{array}{c}0,6 \\
1\end{array}$ & Control Médico & 0 & 51 & 0,89 \\
\hline & 1 & 22 & $\begin{array}{c}0,3 \\
9\end{array}$ & & 1 & 6 & 0,11 \\
\hline \multirow{4}{*}{$\begin{array}{r}\text { Nivel de } \\
\text { Formación }\end{array}$} & 2 & 28 & 0,4 & Frecuencia de Control Médico & 0 & 24 & 0,42 \\
\hline & 1 & 25 & $\begin{array}{c}0,4 \\
4\end{array}$ & & 3 & 11 & 0,19 \\
\hline & 0 & 3 & $\begin{array}{c}0,0 \\
5\end{array}$ & & 2 & 8 & 0,14 \\
\hline & 3 & 1 & $\begin{array}{c}0,0 \\
2\end{array}$ & & 1 & 8 & 0,14 \\
\hline \multirow{2}{*}{$\begin{array}{r}\text { Estado } \\
\text { convivencial }\end{array}$} & 0 & 37 & 0,6 & & 4 & 6 & 0,11 \\
\hline & 1 & 20 & $\begin{array}{c}5 \\
0,3 \\
5\end{array}$ & $\begin{array}{r}\text { Conocimiento de Vacunas } \\
\text { Asociadas }\end{array}$ & 1 & 39 & 0,68 \\
\hline
\end{tabular}




\begin{tabular}{|c|c|c|c|c|c|c|c|}
\hline \multirow{4}{*}{$\begin{array}{r}\text { Enfermedad / } \\
\text { Alteración }\end{array}$} & 1 & 45 & 0,7 & & 0 & 18 & 0,32 \\
\hline & & & 9 & & & & \\
\hline & 0 & 12 & 0,2 & ¿Cuáles Vacunas? & 3 & 39 & 0,68 \\
\hline & & & 1 & & & & \\
\hline \multirow{12}{*}{$\begin{array}{r}\text { ¿Cuáles Enf. } \\
\text { / Alt. ? }\end{array}$} & 0 & 45 & 0,7 & & 0 & 13 & 0,23 \\
\hline & & & 9 & & & & \\
\hline & 1 & 2 & 0,0 & & 2 & 5 & 0,09 \\
\hline & & & 4 & & & & \\
\hline & 2 & 2 & 0,0 & Aplicación de Vacuna & 1 & 32 & 0,56 \\
\hline & & & 4 & Antigripal Anual & & & \\
\hline & 4 & 2 & 0,0 & & 0 & 25 & 0,44 \\
\hline & & & 4 & & & & \\
\hline & 3 & 6 & 0,1 & Aplicación de Vacuna & 1 & 43 & 0,75 \\
\hline & & & 1 & Neumocócica & & & \\
\hline & 3 & 1 & 0,0 & & 0 & 14 & 0,25 \\
\hline & & & 1 & & & & \\
\hline \multirow[t]{4}{*}{ Diagnóstico } & 1 & 43 & 0,4 & Lavado de Manos & 0 & 55 & 0,96 \\
\hline & & & 5 & & & & \\
\hline & 0 & 14 & 0,2 & & 1 & 2 & 0,04 \\
\hline & & & 5 & & & & \\
\hline \multirow{8}{*}{$\begin{array}{r}\text { Episodios de } \\
\text { Gripe }\end{array}$} & 3 & 27 & 0,4 & Ventilación del Hogar con & 0 & 54 & 0,95 \\
\hline & & & 7 & Frecuencia & & & \\
\hline & 0 & 19 & 0,3 & & 1 & 3 & 0,05 \\
\hline & & & 3 & & & & \\
\hline & 1 & 7 & 0,1 & Hábito de Fumar & 1 & 53 & 0,93 \\
\hline & & & 2 & & & & \\
\hline & 2 & 4 & 0,0 & & 0 & 4 & 0,07 \\
\hline & & & 7 & & & & \\
\hline \multirow{8}{*}{$\begin{array}{r}\text { Época } \\
\text { Estacional }\end{array}$} & 2 & 47 & 0,8 & Exposición pasiva al humo de & 1 & 44 & 0,77 \\
\hline & & & 2 & tabaco & & & \\
\hline & 0 & 4 & 0,0 & & 0 & 13 & 0,23 \\
\hline & & & 7 & & & & \\
\hline & 1 & 3 & 0,0 & Exposición en el trabajo a & 1 & 54 & 0,95 \\
\hline & & & 5 & inhalación de productos nocivos & & & \\
\hline & 3 & 3 & 0,0 & & 0 & 3 & 0,05 \\
\hline & & & 5 & & & & \\
\hline Tratamiento & 1 & 52 & 0,9 & Ароуо & 0 & 44 & 0,77 \\
\hline Farmacológic & & & 1 & & & & \\
\hline & & & & & & & \\
\hline
\end{tabular}




\section{CONCLUSIONES}

Los principales resultados dieron cuenta que el $61 \%$ correspondió al grupo etario considerado como edad avanzada y no se registraron datos en la categoría de grandes viejos o longevos. Respecto a la enfermedad respiratoria de mayor prevalencia es la bronquitis de tipo aguda, seguida por el asma, neumonía y EPOC; mostrándose, en general, el estado de salud de la población estudiada con una baja carga de enfermedades respiratorias.

La señal más relevante ha sido lo relacionado al eje prevención, conocimiento y aplicación de vacunas asociadas a enfermedades respiratorias como la antigripal y antineumococica, un $68 \%$ refirió no conocerlas, lo que significa que urge potenciar las acciones de la atención primaria de la salud (APS) en lo que significa la educación en salud, la participación social y la intersectorialidad. Es preciso empoderar a las PAM en esta etapa de la vida a aprender nuevas conductas de adaptación frente a los cambios biológicos, psicológicos y sociales, y sobre todo a potenciar el autocuidado como necesidad básica para mantener la autonomía y como una de las estrategias para la atención de los problemas de salud.

Los resultados permiten por un lado visibilizar el rol de Enfermería comunitaria que la posiciona como actor clave de la comunidad y por otro empoderar a las PAM quienes a través de las organizaciones, en este caso un centros de jubilados, pueden intervenir activamente tomando decisiones y produciendo transformaciones.

El enfoque que se fue desarrollando ha estimado ciertas particularidades de la población en estudio en cuanto al amplio desconocimiento sobre las vacunas como medida preventiva y respecto a la cantidad de adultos mayores que no han tenido la cobertura vacunal de forma satisfactoria. El escenario no es para nada alentador desde esta perspectiva ya que la promoción y prevención son los puntos quizás más fuertes en estrategias de políticas públicas de salud. En lo que respecta a nuestra actualidad y la del futuro, es una situación que preocupa y genera las interrogantes, se suma a una infinidad de estrategias y acciones, y por sobre todo al compromiso en cumplirlas sin dejar vacios.

Es sumamente necesario reconocer que debemos prepararnos, para querer alcanzar una larga vida con calidad inmersos en lo positivo y no en la negación de un futuro cercano. Este podría considerarse, un proceso colectivo permanente de producción de conocimientos a confrontar la realidad que se presenta de forma crítica y lograr leerla para transformarla. Apropiarse de los fenómenos y sus raíces ayuda a comprenderlos en sus diferentes momentos. Esta participación y conciencia no brota espontáneamente, aquí entra la educación para la salud como creadora de esos lugares, convirtiéndose en un instrumento imprescindible para implicar responsablemente a las PAM y la comunidad en la toma de decisiones en defensa y promoción de la salud.

Se recomienda creación de programas, actividades con ejes educativos, a través del proceso de intervención comunitaria reconociéndolo como integrado e integral y estratégico acerca de las enfermedades respiratorias que confiere el presente estudio, de manera que la participación activa y adaptación de las PAM a estos permita el desarrollo de conductas de protección para la salud, mediante la promoción y prevención así mejorar la calidad de vida.

Hoy, en el contexto sanitario de la epidemia de coronavirus COVID-19 en el que finaliza este informe es ineludible la toma de decisiones urgentes para reforzar estrategias de APS en lo que a educación para la salud se refiere, con el fin de minimizar la curva de contagio y hacer viable la prestación en los establecimientos de salud. 


\section{AGRADECIMIENTOS}

A los actores principales del mismo, los Adultos Mayores que conformaron el estudio.

A la Sra. Artaza Míguela y Sr. Gallardo José, representantes del centro de jubilados "Encuentro de Amigos", por la empatía, predisposición, participación y por permitir el ingreso a su sede.

A cada uno de los docentes que supieron acompañar y aportar a la investigación.

A la UNPA-UARG por la oportunidad brindada para el crecimiento académico.

\section{BIBLIOGRAFIA}

ACEVEDO, ALEMÁN. J. TRUJILlO, PÉREZ. MARIA DE LOS ÁNGELES. LÓPEZ, SAUCEDO. MARÍA DE LA LUZ. (2012). Envejeciendo "dignamente": una mirada hacia las condiciones de vida del adulto mayor. Plaza y Valdés, S.A. de C.V.331.México, D.F. [Libro En línea]. Recuperado el 10 de Marzo de 2019, de ProQuest Ebook Central. https://ebookcentral.proquest.com/lib/siunpas

ACOSTA, F. ORLANDO., BATISTA, M. JOSÉ, J., CABRERA, N. PEDRO., CAMINERO, L. J. ANTONIO., SERDÁ, J. GABRIEL., et al. (2005). Manual de enfermedades respiratorias. Unión Internacional Contra la Tuberculosis y Enfermedades Respiratorias.2da Edición. Editores Navarro, Pedro. C., de Castro, Felipe. R., Gilart.

ALEAGA HERNANDEZ, Y. Y., SERRA, VALDES. M. A., y CORDERO, LÓPEZ. G. (2015). Neumonía adquirida en la comunidad: aspectos clínicos y valoración del riesgo en ancianos hospitalizados. Rev. Cubana de Salud Pública, 41(3), 413426.Recuperado de: https://www.medigraphic.com/pdfs/revcubsalpub/csp2015/csp153c.pdf

ALEMÁn, J. A., PÉREZ, M. D. L. A. T. y SAUCEDO, M. D. L. L. L. (2012). Apuntes para una Política Integral de atención al Adulto Mayor: el problema del envejecimiento. (Algunas notas) de la Escuela Nacional de Trabajo Social ENTS, UNAM., 56. Recuperado el 12 de Marzo de 2019, de http://ts.ucr.ac.cr/binarios/libros/libros000024.pdf\#page $=169$

AMPUERO, C., NORAMBUENA, M., y SEGOVIA, M. (2012). La impronta de la migración chilena durante el siglo XX en el Paisaje Urbano de la ciudad de Río Gallegos. Los barrios Belgrano y Nuestra Señora del Carmen como Paisaje Cultural Urbano. Publicado en Memorias de las Jornadas de Reflexión acerca de los Paisajes Culturales de Argentina y Chile, en especial los situados en la Región patagónica, 13, 163. Recuperado el 27 de Abril de 2019.

ASTUDILLO RUNIN, S. (2016). Prevalencia de Neumonía Adquirida en la Comunidad en el Hospital Vitarte en el periodo Julio 2013-Julio 2015.Recuperado el 26 de Marzo de 2019, de http://repositorio.urp.edu.pe/bitstream/handle/urp/463/Astudillo_s.pdf?sequ 
BARROS MONSERRATE, A. C. (2018). Infecciónes respiratorias altas y su incidencia de neumonía en adultos mayores de la parroquia 10 de noviembre del Cantón Ventanas Provincia Los Ríos, periodo septiembre 2017-febrero 2018. (Bachelor's thesis, BABAHOYO, UTB 2018). Recuperado el 24 de Marzo de 2019, de http://dspace.utb.edu.ec/bitstream/49000/3884/1/P-UTB-FCS-TERRE-000016.pdf

BEDOLLA-BARAJAS, M., MORALES- ROMERO, J., HERNÁNDEZ-COLÍN, D. D., y ARÉVALO-CRUZ, D. (2012). Prevalencias de sensibilización a alérgenos más comunes en adultos mayores del Occidente de México. Revista Alergia de México, 59(3). Recuperado de: https://nietoeditores.com.mx/nieto/Alergia/2012/julsep/art.original_prevalencias.pdf.

CARREÑO RODRIGUEZ, V. y NOBLECILLA GRUNAUER, H. (2015). Determinación de la prevalencia, etiología y factores de riesgo para neumonía adquirida en la comunidad, mediante exámenes clínico, laboratorial e imagenológico en pacientes adultos mayores. Hospital Homero Castanier. 2013-2014. (Master's thesis. Recuperado el 25 de Marzo de 2019, de Quito: UCE): http://www.dspace.uce.edu.ec:8080/bitstream/25000/4729/1/T-UCE-0006-130.pdf

CEPAL. (2012).Envejecimiento, solidaridad y protección social: La hora de avanzar hacia la igualdad. LC/L.3451 (CRE.3/3). p.107. Recuperado de: https://www.cepal.org/es/publicaciones/21532-envejecimiento-solidaridad-proteccionsocial-la-hora-avanzar-la-igualdad-tercera

CEPAL-CELADE. (2008). Transformaciones demográficas y su influencia en el desarrollo en América Latina y el Caribe. p.114 Recuperado de: https://repositorio.cepal.org/handle/11362/2894

CORNACHIONE, LARRÍNAGA., MARIA. (2015). Psicología del Desarrollo. Aspectos biológicos, psicológicos y sociales. Vejez. Editorial Brujas. Buenos Aires. Argentina. 264. [Libro En línea] Recuperado el 2 de Marzo de 2019 de: https://ebookcentral.proquest.com/lib/siunpasp/reader.action?docID=4508730

CORRALES, R. (2017). Resfrío común. ARS MEDICA Revista de Ciencias Médicas, 16(2). ,29-33.

ECHAZARRETA, ANDRÉS L., ARIAS, S. J., del OLMO, R., GIUGNO, E. R., COLODENCO, F. D., Arce, S. C.,... y Grupo de estudio EPOC. (2017). Prevalencia de enfermedad pulmonar obstructiva crónica en 6 aglomerados urbanos de Argentina: el estudio EPOC.AR. Arch Bronconeumol. a. Obtenido de http://www.anlis.gov.ar/iner/wp-content/uploads/2017/12/EPOCAR.pdf

FASSIO, A, ROQUE, M (2008). Gerontología comunitaria e institucional. Material de Estudio de la especialización en gerontología comunitaria e institucional. Ministerio de Desarrollo social de la nación- Universidad de Mar del Plata. Argentina

FRÍAS, P. (2007). Estudio comparativo de la delimitación administrativa con la perceptiva de tres barrios de la segunda franja residencial de Río Gallegos. En Actas I Congreso Estudiantil de Historia Regional y Patagónica en el Estrecho de Magallanes". Recuperado el 27 de Abril de 2019, de Universidad de Magallanes. Punta Arenas.

GARCÍA PULGARÍN L. VERÓNICA, GARCÍA ORTIZ L. HERNANDO. (2005). El Adulto Mayor Maduro: Condiciones Actuales de Vida. Revista Médica de Risaralda, vol.11 (2).10. https://dialnet.unirioja.es/descarga/articulo/5030408.pdf 
HAM, CHANDE, R. (2000). Los umbrales del envejecimiento. Estudios Sociológicos. 18(3): 661-676, México, D.F. El Colegio de México, A.C. [Libro En línea]: ProQuest Ebook Central. https://ebookcentral.proquest.com/lib/siunpasp/detail.

INSTITUTO NACIONAL DE ESTADÍSTICA Y CENSOS (INDEC). (2012). https://www.indec.gob.ar/. Recuperado el 10 de Marzo de 2019, de https://www.indec.gob.ar/ftp/cuadros/poblacion/censo2010_tomo1.pdf

INSTITUTO NACIONAL DE ESTADÍSTICA Y CENSOS- INDEC. (2013). Proyecciones Provinciales de Población por Sexo y Grupo de Edad 2010-2040. Serie análisis demográfico $\mathrm{N}^{\mathrm{o}}$ 36. Argentina. Recuperado el 10 de Marzo de 2019, de https://www.indec.gob.ar/ftp/cuadros/publicaciones/proyecciones_prov_2010_2040.pd $\underline{f}$

LECHÓN SÁNCHEZ, L. I. (2017).Incidencia y factores de riesgo asociados a enfermedades respiratorias en Adultos mayores que acuden al Dispensario San Agustín del Seguro Campesino, Otavalo 2016. (Bachelor's thesis). Recuperado el 26 de Marzo de 2019, de http://repositorio.utn.edu.ec/bitstream/123456789/6361/1/06\%20ENF\%20790\%20TR ABAJO\%20DE\%20GRADO.pdf

L. N. 27.491 (2018). Control de Enfermedades Prevenibles por Vacunación. Honorable Congreso de la Nación Argentina 2019. Recuperado el 5 de Abril de 2019, de https://www.argentina.gob.ar/normativa/nacional/ley-27491-318455

LOPARDO, G. D., FRIDMAN, D., RAIMONDO, E., ALBORNOZ, H., LOPADO, A., BAGNULO,H.,... y STAMBOULIAN, D.(2018). Incidence rate of communityacquired pneumonia in adults: a population-based prospective active surveillance study in three cities in South America.BMJ open8 (4), e019439. , https://bmjopen.bmj.com/content/bmjopen/8/4/e019439.full.pdf.

MINISTERIO DE SALUD. (2015). Mortalidad por Enfermedades Respiratorias. Argentina. Recuperado el 2 de Abril de 2019.de: http://www.anlis.gov.ar/iner/wpcontent/uploads/2016/04/Boletin-Mortalidad-por-Enfermedades-Respiratorias-enArgentina-2015.pdf

MINISTERIO DE SALUD. (2015). Primera Encuesta de Prevalencia de Asma en Población de 20 a 44 años. Argentina. Recuperado el 14 de Abril de 2018, de http://www.msal.gob.ar/images/stories/bes/graficos/0000000821cnt-2015-

11 resumen-ejecutivo-ASMA-2015.pdf

MINISTERIO DE SALUD. (2016). Natalidad y Mortalidad. Argentina. Recuperado el 17 de Abril de 2019, de: http://www.deis.msal.gov.ar/wpcontent/uploads/2018/07/Natalidad-Mortalidad-2016-SintesisNro3.pdf

MINISTERIO DE SALUD Y AMBIENTE DE SANTA CRUZ. (2016). Infecciones Respiratorias-Periodo 2011/2015. Datos por Departamento Geográfico. Recuperado el 6 de Marzo de 2019, de http://saludsantacruz.gob.ar/portal/

MINISTERIO DE SALUD (2016). Análisis de Situación de Salud por Cáncer - Un aporte para la toma de decisiones en salud pública basadas en información. Instituto Nacional del Cáncer. Argentina. Recuperado el 17 de Marzo de 2019, de: http://www.msal.gob.ar/images/stories/bes/graficos/0000000925cnt-2016-12-21boletin-epidemiologia.pdf 
MINISTERIO DE SALUD. (2017). Epidemiológica y Recomendaciones para la prevención y Diagnóstico de las Infecciones Respiratorias Agudas. Argentina. Guía de Vigilancia 1. Recuperado el 9 de Abril de 2019, de http://www.ministeriodesalud.chubut.gov.ar/wpcontent/uploads/2018/07/Guia-y-recomendaciones-IRA.pdf

MINISTERIO DE SALUD (2017). Vacunación contra Neumococo. Argentina. Recuperado el 18 de Abril de 2019, de: http://www.msal.gob.ar/images/stories/bes/graficos/0000000947cnt-

Lineamientos_neumo_adultos_WEB.pdf

MINISTERIO DE SALUD. (2018). Análisis de Situación de Salud por Cáncer - Un aporte para la toma de decisiones en salud pública basadas en información. Boletín de Vigilancia Epidemiologica. INC. Argentina. Recuperado el 18 de Marzo de 2019, de: http://www.msal.gob.ar/images/stories/bes/graficos/0000001386cnt-20181213boletin-epidemiologia.pdf

MINISTERIO DE SALUD. (2018). Boletines Integrados. Argentina. Recuperado el 6 de Abril de 2019, de: https://www.argentina.gob.ar/salud/epidemiologia/boletinesepidemiologicos

MINISTERIO DE SALUD. (2019). Vacunación Antigripal. Argentina. Recuperado el 14 de Abril de 2019, de: http://www.msal.gob.ar/images/stories/bes/graficos/0000001437cnt-2019-04_guiaoperativa-vacunacion-antigripal.pdf

MINISTERIO DE SALUD. (2019). Boletín sobre Tuberculosis. Argentina. № 2. Recuperado $\begin{array}{llllll}\text { el } & 10 & \text { de } & 10 & \text { de } & 2019,\end{array}$ http://www.msal.gob.ar/images/stories/bes/graficos/0000001436cnt-2019-03_boletinepidemiologico tuberculosis.pdf

MINISTERIO DE SALUD. Programa ProNEAS- Programa Nacional de Envejecimiento Activo y Salud. Argentina. Recuperado el 29 de Marzo de 2019, de http://www.msal.gob.ar/ent/index.php/programas/proneas

MORENO-ALTAMIRANO, A., LÓPEZ-MORENO, S., y CORCHO-BERDUGO, A. (2000). Principales medidas en epidemiología. Salud pública de México, 42, 337 348.Recuperado el 24 de Marzo de 2019, de https://www.scielosp.org/article/spm/2000.v42n4/337-348/en/

NEUGARTEN B. (1999). Los significados de la Edad. España: Editorial Herder. [Libro En línea]. . Recuperado el 8 de Marzo de 2019, de http://cepsifotocopiadora.com.ar/archivos/folios/39494_2016713.pdf

NORAMBUENA, M., AMPUERO, C., STANOSS, M. S., y CÁCERES, A. P. (2015). Barrios de inmigración chilena en Río Gallegos. Una aproximación a la percepción de los habitantes de la ciudad. Informes Científicos Técnicos-UNPA, 7(1), 261-279.

ODDONE, M. J. (2013). Antecedentes Teóricos del Envejecimiento Activo. Informes Envejecimiento en Red, No4. Recuperado el 19 de Marzo de 2019, de https://ri.conicet.gov.ar/bitstream/handle/11336/28068/CONICET_Digital_Nro.86957 6a3-5273-4ab7-b2f0-06537851e0d5_A.pdf? sequence=2\&isAllowed=y 
ORTIZ, ZULMA., ESANDI M. EUGENIA., BORTMAN, MARCELO. (2004). Módulos de Epidemiologia Básica y Vigilancia de la Salud. Introducción a la Epidemiologia. Segunda edición. Programa de Vigilancia de la Salud y Control de Enfermedades. Ministerio de Salud. Argentina. Recuperado el 29 de Marzo de 2019, de http://www.msal.gob.ar/images/stories/ministerio/presec-2012/epidemiologia-basicay-vigilancia-modulo-1.pdf

ORGANIZACIÓN MUNDIAL DE LA SALUD (OMS). (2002). Envejecimiento Activo: un marco político. Editores OMS, $\mathrm{N}^{\mathrm{o}}$ de pág. 59. Publicación Abril de 2002. $\mathrm{N}^{\mathrm{o}}$ de referencia WHO/NMH/NPH/02.8. Recuperado de: https://apps.who.int/iris/bitstream/handle/10665/67215/WHO_NMH_NPH_02.8.pdf?s equence=1. Versión en Español: Transmisibles, G. O. D. E. N., \& Mental, S. (2002). Envejecimiento activo: un marco político. Rev Esp Geriatr Gerontol, 37(S2), 74105.Recuperado de: http://envejecimiento.csic.es/documentos/documentos/omsenvejecimiento-01.pdf.

ORGANIZACIÓN MUNDIAL DE LA SALUD (OMS). (2015). Informe Mundial sobre el Envejecimiento y la Salud. Recuperado el 18 de Marzo de 2019, de https://apps.who.int/iris/bitstream/handle/10665/186466/9789240694873_spa.pdf?seq $\underline{\text { uence }=1}$

ORGANIZACIÓN MUNDIAL DE LA SALUD (OMS). (2016). Neumonía. Recuperado el 3 de Abril de 2019, de https://www.who.int/es/news-room/fact-sheets/detail/pneumonia

ORGANIZACIÓN MUNDIAL DE LA SALUD (OMS). (2017). Asma. Recuperado el 22 de Marzo de 2019, de https://www.who.int/es/news-room/fact-sheets/detail/asthma

ORGANIZACIÓN MUNDIAL DE LA SALUD (OMS). (2017). Enfermedad Pulmonar Obstructiva Crónica (EPOC).Recuperado el 20 de Marzo de 2019, de https://www.who.int/es/news-room/fact-sheets/detail/chronic-obstructive-pulmonarydisease-(copd)

ORGANIZACIÓN MUNDIAL DE LA SALUD (OMS). (2018). Tuberculosis. Recuperado el 23 de Marzo de 2019, de. Recuperado de: https://www.who.int/es/news-room/factsheets/detail/tuberculosis

ORGANIZACIÓN MUNDIAL DE LA SALUD (OMS). (2018). Cáncer. Recuperado el 14 de Abril de 2019, de https://www.who.int/es/news-room/fact-sheets/detail/cancer

ORGANIZACIÓN MUNDIAL DE LA SALUD (OMS). (2018). Gripe. Recuperado el 14 de Abril de 2019, de https://www.who.int/es/news-room/fact-sheets/detail/influenza$\underline{\text { (seasonal) }}$

ORGANIZACIÓN MUNDIAL DE LA SALUD (OMS). (S.f). Envejecimiento y Ciclo de Vida. Datos de interés acerca del envejecimiento. Recuperado el 10 de Marzo de 2019, de https://www.who.int/ageing/about/facts/es/

PANDO HERNÁNDEZ, E. Y., MILÓ VALDÉS, C. A., MARRERO PÉREZ, M., MENA HERNÁNDEZ, V. M., y DÍAZ ALFONSO, H. (2018). Caracterización de pacientes con neumonía bacteriana adquirida en la comunidad ingresados en un hospital provincial pinareño. Universidad Médica Pinareña, 14(3), , 229-237.

PARDO ANDREU, G. (2003). Consideraciones generales sobre algunas de las teorías del envejecimiento. Rev. Cubana de Investigaciones Biomédicas, 22(1). http://scielo.sld.cu/scielo.php?script=sci_arttext\&pid=S0864-03002003000100008. 
PARDO CAPA, D. T. (2018). Conocimiento y cobertura vacunal sobre influenza y neumonía en adultos mayores del Centro de Salud El Cambio del cantón Machala. Recuperado el 28 de Marzo de 2019, de https://scholar.google.com/scholar?hl=es\&as_sdt=0\%2C5\&q=CONOCIMIENTO+Y+ COBERTURA+VACUNAL+SOBRE+INFLUENZA+Y+NEUMON\%C3\%8DA+EN + ADULTOS+MAYORES+DEL+CENTRO+DE+SALUD+EL+CAMBIO+DEL+CA NT\%C3\%93N+MACHALA.\&btnG=\#d=gs_cit\&u=\%2Fscholar\%3Fq\%3Dinfo $\% 3 \mathrm{AN}$ ZisU95xERIJ\%3Ascho

PEÑA, M. J. A., MACÍAS, N. N. I., y MORALES, A. F. L.(2011). Manual de práctica básica del adulto mayor. (2a. ed.). [Libro En línea]. Recuperado el 11 de Marzo de 2019, de https://ebookcentral.proquest.com

PEÑAFIEL, A., y MONTES, D. R. P. (2011). Perfil epidemiológico Red de Salud de Ladera ESE Año 2010. Recuperado el 07 de Marzo de 2019, de http://calisaludable.cali.gov.co/planeacion/2012_ConcursoESE/Plan_Gerencial/Ese_L adera/epidemiologico-ladera.pdf

PÉREZ PACARÉU, M. GONZÁLEZ PAREDES, A., ROMERO CABRERA, J., RAMIREZ LÓPEZ, N., ÁLVAREZ TOLEDO, I., y MACÍAS CARRERA, V. (2011). Asma bronquial en el adulto mayor: una aproximación a esta temática en Cuba. MediSur, 9(1), 43-48. Recuperado el 22 de Marzo de 2019, de http://scielo.sld.cu/scielo.php?script=sci_arttext\&pid=S1727-897X2011000100008

PETRETTO, D. R., PILI, R., GAVIANO, L., LÓPEZ, C. M., y ZUDDAS, C. (2016). Envejecimiento activo y de éxito o saludable: una breve historia de modelos conceptuales. Revista Española de Geriatría y Gerontología, 51(4). Española de Geriatría y Gerontología, 2016, vol. 51, no 4, p. 229-241. , 229-241 https://www.sciencedirect.com/science/article/abs/pii/S0211139X1500205X.

QUECAÑA, H. E., EDUARDO, J., y MARTÍNEZ, J. I. (2016). Reincidencia de pacientes adultos mayores con neumonías en el servicio de clínica médica de hospitales privados de Mendoza. (Doctoral dissertation, Universidad Nacional de Cuyo. Facultad de Ciencias Médicas. Escuela de Enfermería.). Recuperado el 14 de 3 de 2019, de https://scholar.google.es/scholar?hl=es\&as_sdt=0\%2C5\&q=Reincidencia+de+paciente $\underline{\mathrm{s}+\text { adultos+mayores+con+neumon\%C } 3 \% \mathrm{ADas}+\mathrm{en}+\mathrm{el}+\text { servicio+de+c1\%C3\%ADnica+ }}$ m\%C3\%A9dica+de+hospitales+privados+de+Mendoza\&btnG $=$

RAIDEL, GONZÁLEZ. R. (2017). Algunas variables relacionadas con la neumonía adquirida en la comunidad en un área de salud. In Cuba Salud 2018. Recuperado el 26 de Marzo de 2019 ,

de http://www.convencionsalud2017.sld.cu/index.php/connvencionsalud/2018/paper/vie $\underline{\text { wFile } / 49 / 282}$

ROCHA, C., REYNOLDS, N. D., y SIMONS, M. P. (2015). Resistencia emergente a los antibióticos: una amenaza global y un problema crítico en el cuidado de la salud. Revista Peruana de Medicina Experimental y Salud Pública, 32(1). , 139-145 http://www.scielo.org.pe/scielo.php?pid=S1726$\underline{46342015000100020 \& \text { script }=\text { sci arttext\&tlng }=\text { en }}$. 
ROMERO CHICA, JOSE. J., VERGARA ROMERO, L. (2018). Factores de riesgo y su relación con la bronquitis crónica en adultos mayores de la ciudadela 4 de mayo, Babahoyo Los Ríos, periodo septiembre 2017 a febrero 2018. (Bachelor's thesis, BABAHOYO, UTB 2018). Recuperado el 24 de Marzo de 2019, de http://dspace.utb.edu.ec/handle/49000/3904

SALGADO ALBERTO, GUILLEN. F. (1990). Manual de Geriatría. España. Editorial Masson. [Libro Manual].

SCHULLER, P. A. (1999).Aspectos Médicos del Envejecimiento. Publicación Madrid Fundación General de la Universidad Autónoma de Madrid. [Libro En línea]: Retrieved from https://ebookcentral.proquest.com

TABLOSKI, PATRICIA. A. (2010). Enfermería Gerontológica. España. Editorial PEARSON. 2da Edición. 936. [Libro Manual]

TOUCEDA, MARÍA. A., RUBIN, ROMINA., GARCIA, JOSÉ. C. (2015). Módulo 4-Salud, Epidemiología y Envejecimiento. Especialización en Gerontología Comunitaria e Institucional - Ministerio Desarrollo Social Presidencia de la Nación. Secretaria Nacional de Niñez, Adolescencia y Familia. Facultad de Psicología Universidad Nacional de Mar del Plata.ISBN:978-987-544-499-7-Recuperado de: https://www.desarrollosocial.gob.ar/wp-content/uploads/2015/05/Gerontolog--aComunitaria-Modulo-41.pdf

VILLAMIL, C. MONTAÑÉZ, M. (2004). ¿Qué es la Gerontología? [Libro En línea]. Obtenido de http://weblog.maimonides.edu/gerontologia2004/archives/000130.html

VALHONDO, A. M., RUBIO, C. F., y CASTRO, P. G. (2006). Familia y Envejecimiento. Disfunciones y Programas Psicoterapéuticos. International Journal of Developmental and Educational Psychology, 2(1). Red de Revistas Científicas de América Latina, el $\begin{array}{llll}\text { Caribe, } & \text { España } & \text { y } & \text { Portugal, }\end{array}$ https://www.redalyc.org/pdf/3498/349832312023.pdf

VILLARROEL CÉSPEDES, I. S. (2018). Perfil epidemiológico del adulto mayor de la provincia de Tungurahua en el 2016. (Bachelor's thesis, Universidad Técnica de Ambato-Facultad de Ciencias de la Salud-Carrera de Terapia Física). Recuperado el 14 de Marzo de 2019, de https://repositorio.uta.edu.ec/bitstream/123456789/28516/2/Santiago\%20villarroel.pdf

VILLEGAS BENAVIDES, L. F. (2017). Prevalencia de afecciones respiratorias en el servicio de medicina física y rehabilitación del hospital IESS Ambato. (Bachelor's thesis, Universidad Técnica de Ambato-Facultad de Ciencias de la Salud-Carrera de Terapia Física). Recuperado el 27 de Marzo de 2019, de https://repositorio.uta.edu.ec/bitstream/123456789/25971/1/TESISLUIS\%20VILLEGAS.pdf

VILLEGAS, C., DE LA ROSA, V., y NAVARRETE, E. (2013). Clasificación del adulto mayor según el estado de salud y descripción del proceso de envejecimiento. (Doctoral dissertation, Tesis de Licenciatura en enfermería. Recuperado el 6 de Marzo de 2019, de Xochimilco: Universidad Autónoma Metropolitana unidad Xochimilco, Departamento de Atención a la Salud): https://www.medigraphic.com/cgibin/new/medigraphic.cgi 
YÁÑEZ, A. \&. BUENO, C. (2016). Asma en Adultos Mayores. Asthma in older adults. AAIC - ARCHIVOS DE ALERGIA E INMUNOLOGÍA CLÍNICA, 47(4). , 140-145. http://adm.meducatium.com.ar/contenido/articulos/12001400145_805/pdf/120014001 $\underline{45 . p d f}$

YÉPEZ GRANIZO, M. G. (2016). Características socio-demográficas y clínico geriátricas asociados con depresión en adultos mayores que acuden al servicio de consulta externa en el hospital de atención integral del adulto mayor, por el lapso de cinco meses entre el 2014 y 2015. Recuperado el 2 de Marzo de 2019, de (Bachelor's thesis, PUCE): http://repositorio.puce.edu.ec/bitstream/handle/22000/11184/Tesis.pdf?sequence $=1 \&$ is Allowed $=\mathrm{y}$

YUNI JOSÉ A., URBANO. CLAUDIO. A. (2005). Educación de Adultos Mayores. Teoría, investigación e intervenciones. Argentina: Editorial Brujas. 17-265. [Libro Manual].

YUNI, JOSÉ. A. URBANO, CLAUDIO. A. (2016).Envejecer Aprendiendo: Claves para un Envejecimiento Activo. Editorial Brujas. [Libro -En línea].Recuperado el 19 de Marzo de 2019, de ProQuest Central. https://ebookcentral.proquest.com/lib/siunpasp/detail.actio 